\title{
The Integration of Multilateral Environmental Agreements: Lessons from the Biodiversity-Related Conventions
}

\author{
Richard Caddell
}

\section{INTRODUCTION}

It is a well-worn truism that modern international environmental law has developed at an astonishing rate. From humble beginnings, an expansive cohort of instruments and actors has emerged to address a wide variety of ecological threats. Nevertheless, concerns have been consistently raised by commentators, activists, and institutions that this sprawling network has advanced largely at the expense of structural coherence. Indeed, as observed by the Governing Council of the UN Environment Programme (UNEP), '[w] hereas the creation of the various legally-binding conventions and protocols on the environment constitutes an outstanding achievement on the part of the international community, it also raises the need for continuing policy coherence among the various instrumentalities that exist in this area at both the inter-agency and intergovernmental levels. ${ }^{1}$ Improving global environmental governance therefore represents both a significant challenge and a pressing concern for the international community.

These practical difficulties are attributable largely to the inherent nature of international environmental law making. The emergence of such treaties is often the product of disparate political motivations, pressures on certain valued natural resources, regulatory reactions to specific events, and the catalyzing effect of periodic inter-governmental processes to establish overarching global goals. Consequently, environmental treaties have tended to emerge in a relatively unco-ordinated and ad hoc manner. In the early 1990s, the phenomenon of 'treaty congestion' was identified as afflicting the environmental treaties that emerged in the wake of the 1972 UN Conference on the Human Environment. While this term remains obscure from a legal perspective, ${ }^{2}$ it may be broadly

The author is indebted to the Yearbook editors for their insightful comments on previous drafts, yet he remains solely responsible for the content.

1 UN Environment Programme (UNEP), Report of the Executive Director of the Seventh Special Session of the Governing Council of the United Nations Environment Programme, Document UNEP/ GCSS.VII/2 (2002) at 5.

2 B.L. Hicks, Treaty Congestion in International Environmental Law: The Need for Greater International Coordination 32 U Richmond L Rev 1643 at 1646 (1999).

(C) The Author 2012. Published by Oxford University Press. All rights reserved. For permissions, please e-mail: journals.permissions@oup.com 
considered to connote regulatory inefficiencies created by 'overlapping provisions in agreements, inconsistencies in obligations, significant gaps in coverage, and duplication of goals and responsibilities. ${ }^{3}$ With further instruments having proliferated since the 1992 UN Conference on Environment and Development, forging effective linkages between regimes has become an increasingly necessary, yet complicated, aspect of multilateral practices.

In recent years, multilateral environmental agreements (MEAs) have sought to mitigate these difficulties by streamlining administrative procedures, pooling resources, and advancing collaborative actions on issues of mutual concern. Two primary mechanisms have been developed to this end. First, treaties sharing broadly similar aims and applications have formed executive 'clusters' to facilitate a common vision and overarching implementation strategies. Second, and more widespread, individual MEAs have forged co-operative agreements to promote mutually supportive actions. However, despite these increasingly common features of MEA governance, the results of inter-treaty co-operation have been subject to surprisingly little evaluation.

This article appraises the practical application of these strategies by examining the biodiversity-related conventions (BRCs), a key 'cluster' of treaties that are concerned with nature conservation, either by regulating single or collective species or through their application to particular types of natural habitats. In chronological order, these treaties comprise the 1971 Convention on Wetlands of International Importance, Especially as Waterfowl Habitat (Ramsar Convention), ${ }^{4}$ the 1972 Convention Concerning the Protection of the World Cultural and Natural Heritage (World Heritage Convention), ${ }^{5}$ the 1973 Convention on International Trade in Endangered Species of Wild Fauna and Flora (CITES), ${ }^{6}$ the 1979 Convention on Migratory Species of Wild Animals $(\mathrm{CMS}){ }^{7}$ the 1992 Convention on Biological Diversity (CBD), ${ }^{8}$ and, latterly, the 2001 International Treaty on Plant Genetic Resources for Food and Agriculture (ITPGRFA). ${ }^{9}$

The BRCs have invested significant volumes of time and resources to purportedly improve inter-treaty co-ordination, yet doubts remain over whether

\footnotetext{
3 E. Brown Weiss, International Environmental Law: Contemporary Issues and the Emergence of a New World Order 81 Georgetown LJ 675 at 699 (1993).

4 Convention on Wetlands of International Importance, Especially as Waterfowl Habitat, 996 UNTS 245 [Ramsar Convention].

5 Convention Concerning the Protection of the World Cultural and Natural Heritage, 1037 UNTS 151 [World Heritage Convention].

6 Convention on International Trade in Endangered Species of Wild Fauna and Flora, 993 UNTS 243 [CITES].

7 Convention on Migratory Species of Wild Animals, 1651 UNTS 333 [CMS].

8 Convention on Biological Diversity, 1790 UNTS 79 [CBD].

9 International Treaty on Plant Genetic Resources for Food and Agriculture, 2004 UNTS 303 [ITPGRFA].
} 
these endeavours have delivered tangible results. ${ }^{10}$ Based on an evaluation of the current state of co-operation between the BRCs, this article will argue that the various linkage initiatives have had modest successes to date, as they have often lacked direction, clear lines of responsibility and are frequently undermined by resource constraints. Conversely, it will be demonstrated that synergy projects that are clearly targeted, well-organized, and encompass a natural demarcation of responsibility between actors have the potential to deliver genuine conservation benefits and administrative improvements. This analysis will demonstrate, however, that such benefits depend upon a high degree of compatibility of subject matter and purpose between regimes, underpinned by effective oversight and adequate funding. These findings suggest that the BRCs may ultimately be better served in prioritizing smaller, self-contained areas of common focus, such as individual species or specific conservation threats, as opposed to the current perceived emphasis on generic executive synergies.

To this end, the second part of this article introduces the institutional and treaty-derived scope for collaborative practices. The third part outlines the evolution of current synergies, demonstrating that clustering arrangements have proved generally ineffective in the case of the BRCs in comparison with more specific policies developed between treaties on common issues. The fourth part of the article addresses the major impediments to effective co-ordination, while the fifth part advances a series of concise conclusions.

\section{THE LEGAL BASIS FOR INTER-TREATY CO-OPERATION}

\section{The Development of Institutional Synergies}

The BRCs exemplify - and have essentially pioneered-a distinct model of institutional governance that is now ubiquitous among MEAs. In contrast to the traditional deployment of inter-governmental organizations (IGOs), a trend has emerged since 1972 towards the creation of 'autonomous institutional arrangements,' providing a flexible, sui generis approach to specific concerns under their treaty mandates. ${ }^{11}$ These arrangements typically encompass a decisionmaking organ, christened with a variety of nomenclature, but most commonly referred to as a Conference of the Parties (COP). This is the most significant feature of these arrangements and provides a regular forum for the parties to elaborate institutional policies. The COP shapes the practical direction of the treaty and further elaborates the obligations incumbent upon the parties. ${ }^{12}$ The COP is usually supported by an ancillary body, providing day-to-day policy

\footnotetext{
10 A. Jóhannsdóttir, I. Cresswell, and P. Bridgewater, The Current Framework for International Governance of Biodiversity: Is It Doing More Harm Than Good? 19 RECIEL 139 at 148 (2010).

11 R.R. Churchill and G. Ulfstein, Autonomous Institutional Arrangements in Multilateral Environmental Agreements: A Little-Noticed Phenomenon in International Law 94 AJIL 623 (2000).

12 A. Wiersema, The New International Law-Makers? Conferences of the Parties to Multilateral Environmental Agreements 31 Michigan J Int'l L 231 at 237-45 (2009).
} 
management between its meetings, often termed a Standing Committee. These arrangements are bolstered by a designated administrative forum, usually known as a Secretariat, which is generally endowed with limited powers derived mainly from the COP. ${ }^{13}$ This institutional model is often completed by a scientific or technical body, charged with providing specialist advice to develop further operational policies and priorities. This broad template has subsequently become a standard feature of many global and regional environmental instruments. ${ }^{14}$

As this article will demonstrate, co-operative practices have emerged between the various institutions of the BRCs, primarily at the Secretariat and scientific levels and largely at the behest of their COPs. Accordingly, in establishing the scope for present and future collaboration between these treaties, it is first necessary to briefly outline their broad institutional frameworks.

\section{A. Executive Arrangements}

The institutional template adopted by most modern MEAs was initially, and somewhat experimentally, pioneered by the Ramsar Convention and further refined by later instruments. ${ }^{15}$ The Ramsar Convention was the first such body to establish a COP as a distinct management forum, although the 'fairly embryonic creature' envisaged by the original treaty bore little resemblance to subsequent arrangements within the BRCs. ${ }^{16}$ The Ramsar Convention's COP was initially intended to convene 'as the necessity arises,' retaining a purely 'advisory character.' ${ }^{17}$ A combination of the successes of these sporadic meetings and an appreciation of the benefits of permanent arrangements under other treaties prompted a revision of this position, with the COP subsequently placed on a more official footing. Ordinary COP meetings occur every three years, providing a forum to review the implementation of the convention. The COP may adopt non-binding resolutions or recommendations, hence the value of the Ramsar Convention essentially 'lies in its ability to inform and persuade,' 18 although some parties have interpreted these pronouncements as formal obligations to act. ${ }^{19}$

Building upon this model, CITES has also developed an innovative executive structure, albeit one that is primarily concerned with maintaining national bodies

\footnotetext{
13 For a full outline of this issue, see B.H. Desai, Multilateral Environmental Agreements: Legal Status of the Secretariats, especially 101-69 (2010).

14 For a helpful survey of these arrangements see V. Röben, Institutional Developments under Modern International Environmental Agreements 4 Max Planck Y UN L 363 (2000).

15 M. Bowman, P. Davies, and C. Redgwell, Lyster's International Wildlife Law, at 404 (2010).

16 Churchill and Ulfstein, supra note 11 at 629. However, CITES was the first such body to formally term its executive organ a 'Conference of the Parties.' Ibid. at 630.

17 Ramsar Convention, supra note 4, Article 6.

18 R.C. Gardner, K.D. Connolly, and A. Bamba, African Wetlands of International Importance: Assessments of Benefits Associated with Designations under the Ramsar Convention 21 Colorado J. Int'1 Envt'1 L. \& Pol'y 257 at 265 (2008).

19 Wiersema, supra note 12 at 268-70 (noting the practice of the Netherlands).
} 
to discharge its constituent commitments. ${ }^{20}$ The COP to CITES is convened biennially and is responsible for reviewing the implementation of the convention, ${ }^{21}$ with particular emphasis on considering amendments to the convention's appendices $^{22}$ and making recommendations for improving the effectiveness of the convention, ${ }^{23}$ primarily through the adoption of resolutions and decisions.

The CMS also follows this broad approach and convenes a COP 'at intervals of not more than three years. ${ }^{24}$ The COP has a broad remit to review the implementation of the convention, ${ }^{25}$ again primarily through the adoption of resolutions and recommendations. The position within the CMS is complicated further by its innovative structure, which provides for the establishment of additional subsidiary instruments to address particular species. ${ }^{26}$ Two types of instrument are envisaged for qualifying species, namely an AGREEMENT established under the auspices of Article IV(3) of the convention or an agreement concluded pursuant to Article IV(4). ${ }^{27}$ The CMS also generates non-binding instruments, commonly memoranda of understanding (MOUs), as well as less formalized action plans and initiatives, which may ultimately evolve into more structured subsidiaries. Numerous subsidiary instruments have been established thus far, encompassing four Article IV(3) AGREEMENTS, ${ }^{28}$ three Article IV(4) agreements, ${ }^{29}$ and some nineteen MOUs. ${ }^{30}$ The sprawling structure of the CMS creates particular challenges in maintaining institutional coherence, necessitating linkages not only with its fellow BRCs but also with an expanding brood of daughter instruments. These subsidiaries, which have proven equally adept at co-ordinating with other pertinent bodies, have also established their own unique frameworks, largely modelled upon that of the

20 Parties designate national Management Authorities, which are charged with granting permits and certificates for the import and export of listed species, and Scientific Authorities, which provide advice and guidance on the merits of issuing such permits. CITES, supra note 6, Article IX.

21 Ibid., Article XI.

22 Ibid., Article XI(3)(b).

23 Ibid., Article XI(3)(e).

24 CMS, supra note 7, Article VII(3).

25 Ibid., Article VII(5).

26 R. Caddell, International Law and the Protection of Migratory Wildlife: An Appraisal of Twenty-Five Years of the Bonn Convention 16 Colorado J. Int'1 Envt'1 L. \& Pol'y 113 at 118-23 (2005).

27 The term AGREEMENT is emphasized in capitals by the convention's institutions to distinguish such instruments from those established under Article IV(4). CMS, supra note 7, Article IV; see also Resolution 2.6: Implementation of Articles IV and V of the Convention (1988).

281991 Agreement on the Conservation of Populations of European Bats, 1863 UNTS 101 [EUROBATS]; 1995 African-Eurasian Waterbird Agreement, 2365 UNTS I-42632 [AEWA]; 2001 Agreement on the Conservation of Albatrosses and Petrels, 2258 UNTS 257 [ACAP]; 2007 Agreement on the Conservation of Gorillas and Their Habitats, 2544 UNTS I-45400 [Gorilla Agreement].

291990 Agreement on the Conservation of Seals in the Wadden Sea, online: <http://www .waddensea-secretariat.org > [Wadden Sea Seal Agreement]; 1991 Agreement on the Conservation of Small Cetaceans of the Baltic, North-East Atlantic, Irish and North Seas, 1772 UNTS 217 [ASCOBANS]; 1996 Agreement on the Conservation of Cetaceans of the Black Sea, Mediterranean Sea and Contiguous Atlantic Area, 2183 UNTS 303 [ACCOBAMS].

30 CMS, online: <http://www.cms.org >. 
parent convention. There is no specific template for subsidiary instruments within the CMS family, although a consistent theme remains the provision of a regular management forum for the parties, mirroring the COP to the CMS, most commonly in the form of a Meeting of the Parties (MOP) in the case of a legally binding instrument, ${ }^{31}$ or 'regular meetings' ${ }^{32}$ for the MOUs. ${ }^{33}$

The CBD has likewise developed a strong institutional structure, comprising a decision-making organ operating in association with its administrative and scientific bodies. The COP, established under Article 23 of the CBD, meets at 'regular intervals' and exercises broad functions to review progress towards the implementation of the convention. ${ }^{34}$ In this respect, the COP is primarily concerned with proposed amendments and the development of additional protocols to the convention, as well as establishing subsidiary bodies as required to provide specialist advice and to developing 'appropriate forms of cooperation' with the executive bodies of similar treaty regimes. ${ }^{35}$

In a similar vein, the ITPGRFA maintains an institutional structure broadly reminiscent of the other BRCs. A Governing Body fulfils the traditional

31 ACAP, supra note 28, Article VIII; ACCOBAMS, supra note 29, Article III; AEWA, supra note 28, Article VI; ASCOBANS, supra note 29 at para. 5; EUROBATS, supra note 28, Article V; Gorilla Agreement, supra note 28, Article V. The Wadden Sea Seal Agreement, supra note 29, undertakes to work through the existing management institutions of the Wadden Sea Secretariat (at preamble).

321993 MOU Concerning Conservation Measures for the Siberian Crane (paragraph 2); 1999 MOU Concerning Conservation Measures for Marine Turtles of the Atlantic Coast of Africa (paragraph 3); 2001 MOU on the Conservation and Management of Marine Turtles and Their Habitats of the Indian Ocean and South-East Asia (paragraph 3 of the 'Basic Principles' section); 2001 MOU on the Conservation and Management of the Middle-European Population of the Great Bustard (unnumbered) [Great Bustard MOU]; 2002 MOU Concerning Conservation and Restoration of the Bukhara Deer (Cervus elaphus batrianus) (paragraph 2) [Bukhara Deer MOU]; 2003 MOU Concerning Conservation Measures for the Aquatic Warbler (paragraph 3) [Aquatic Warbler MOU]; 2005 MOU Concerning the Conservation, Restoration and Sustainable Use of the Saiga Antelope (Saiga spp.) (paragraph 3); 2005 MOU Concerning Conservation Measures for the West African Populations of the African Elephant (Loxodonta africana) (paragraph 5) [West African Elephants MOU]; 2006 MOU for the Conservation of Cetaceans and Their Habitats in the Pacific Islands Region (paragraph 6); 2006 MOU between the Argentine Republic and the Republic of Chile on the Conservation of the Ruddy-Headed Goose (paragraph 8); 2007 MOU on the Conservation and Management of Dugongs (Dugong dugon) and Their Habitats throughout Their Range (paragraph 6); 2007 MOU on the Conservation of Southern South American Migratory Grassland Bird Species and Their Habitats (paragraph 4); 2007 MOU Concerning Conservation Measures for the Eastern Atlantic Populations of the Mediterranean Monk Seal (Monachus monachus) (paragraph 5) [Mediterranean Monk Seal MOU]; 2008 MOU on the Conservation of High Andean Flamingos and Their Habitats (paragraph 4); 2008 MOU on the Conservation of Migratory Birds of Prey in Africa and Eurasia (paragraph 13, listing this forum as a 'Meeting of the Signatories'); 2008 MOU Concerning the Conservation of the Manatee and Small Cetaceans of Western Africa and Macaronesia (paragraph 6); 2010 MOU between the Argentine Republic and the Republic of Chile on the Conservation of the South Andean Huemul (Article 8); 2010 MOU on the Conservation of Migratory Sharks (Section 6, again termed a 'Meeting of the Signatories'). All MOUs are reproduced in full on the CMS institutional website.

33 The sole exception is the 1994 MOU concerning Conservation Measures for the Slender-Billed Curlew, which is administered through correspondence or personal contact with central CMS staff.

$34 \mathrm{CBD}$, supra note 8, Article 23(1). The COP is convened on an approximately biennial basis, although the first three COPs were held in successive years.

35 Ibid., Article 23(4). 
functions of a COP, reviewing implementation of the treaty and adopting decisions by consensus. ${ }^{36}$

The institutional arrangements under the World Heritage Convention differ considerably from those of the other BRCs, although the overarching model of executive, administrative, and advisory fora is replicated within this structure. Its most visible institution is the World Heritage Committee, established under Article 8, which operates within the overarching framework of the UN Educational, Social, and Cultural Organization (UNESCO) and comprises a cohort of at least forty rotating members. These members are elected by another executive body under the World Heritage Convention, the General Assembly of States Party, which meets during the sessions of the UNESCO General Conference. Within the committee, leadership is provided by a Bureau of seven individuals, who co-ordinate the work and agenda of its meetings. The committee is charged with overseeing the World Heritage List, by assessing proposed $\operatorname{sites}^{37}$ and potentially de-listing existing areas. ${ }^{38}$ A further 'List of World Heritage in Danger' is maintained by the committee, drawing attention to natural and anthropogenic pressures on the site. The committee is also responsible for administering the World Heritage Fund, which underwrites conservation and preservation activities for sites on the World Heritage List. ${ }^{39}$

\section{B. Administrative Arrangements}

The Ramsar Convention again pioneered the basis for a formal administrative organ that, as with its COP, has steadily evolved in light of refinements to this model by subsequent biodiversity treaties. The convention established a Bureau, provided by the International Union for the Conservation of Nature (IUCN), on what was initially envisaged as a transitional basis. ${ }^{40}$ The Bureau accordingly undertakes a workload that far exceeds its purported mandate. ${ }^{41}$ With no other administrative body envisaged under the convention, the parties have subsequently converted the Bureau into a 'Secretariat'-if, indeed, there was ever any operational difference-to convey its titular functions in a more orthodox fashion and, significantly, to bolster its external relations and credibility. ${ }^{42}$ The Secretariat therefore performs the various administrative, organizational,

36 ITPGRFA, supra note 9, Article 19.

37 World Heritage Convention, supra note 5, Article 11(2).

38 G.P. Buzzini and L. Condorelli, Article 11: List of World Heritage in Danger and Deletion of a Property from the World Heritage List, in F. Francioni (ed.), The 1972 World Heritage Convention: A Commentary, 175-200 at 196-99 (2008).

39 World Heritage Convention, supra note 5, Articles 15-18.

40 Ramsar Convention, supra note 4, Article 8(1). The International Union for the Conservation of Nature (IUCN) has nonetheless continued to fulfil this role to date.

41 Bowman, Davies, and Redgwell, supra note 15 at 431-32.

42 Ramsar Convention, supra note 4, Resolution IX.10 on the Use of the Term and Status of the Ramsar 'Secretariat' (2008). 
outreach, and synergy programs associated with its counterparts among the other BRCs.

Similarly, Article 14 of the World Heritage Convention made provision for a Secretariat, bequeathed by the UNESCO's director-general. In 1992, a new institution, the World Heritage Centre, was established to perform this role. ${ }^{43}$ The ITPGRFA also provides for a 'secretary,' which undertakes the standard administrative functions, including liaison with other bodies. ${ }^{44}$ The CMS also operates a Secretariat which, alongside standard administrative roles, promotes liaison between the parties, the institutions established under its various subsidiary instruments and with other relevant international organizations concerned with migratory species. ${ }^{45}$ The subsidiary instruments also retain varying degrees of administrative autonomy: most agreements operate their own secretariats with the MOUs reliant on the parent convention for organizational support, while the Agreement on the Conservation of Small Cetaceans of the Baltic, North East Atlantic, Irish and North Seas (ASCOBANS) maintains a unique arrangement of sharing a joint institution with the wider CMS Secretariat.

The CBD also follows this broad approach with a designated Secretariat established under the convention, ${ }^{46}$ although as noted later in this article this proactive body enjoys a greater array of external freedoms than its counterparts within the other BRCs. Some divergence is also encountered in the case of CITES, where the Secretariat is primarily tasked with providing administrative support but is also competent to make recommendations for the further implementation of the convention and to invite the attention of the Parties to any matter pertaining to the aims of the present Convention.' ${ }^{47}$

\section{Scientific and Technical Arrangements}

The development of a specialist scientific body to guide management policies was essentially pioneered by the International Whaling Commission (IWC). ${ }^{48}$ The CMS was among the first of the BRCs to create such an institution, with the convention's text mandating the establishment of a Scientific Council at the first COP. ${ }^{49}$ The Scientific Council is a potentially voluminous body, with any contracting party entitled to assign a 'qualified expert,' with additional experts appointed by the $\mathrm{COP},{ }^{50}$ which retains control over its precise

\footnotetext{
43 A.F. Vrdoljak, Article 14: The Secretariat and Support of the World Heritage Committee, in Francioni, supra note 38 at 245-51.

44 ITPGRFA, supra note 9, Article 20.

45 CMS, supra note 7, Article IX.

46 CBD, supra note 8, Article 24.

47 CITES, supra note 6, Article XII.

48 Article III of the Whaling Convention, infra note 115.

49 CMS, supra note 7, Article VIII(1).

50 Ibid., Article VIII(2).
} 
functions. ${ }^{51}$ Technical capacity also varies among the various subsidiary instruments. Some agreements have created specific institutions, ${ }^{52}$ similar to the parent convention, while others share these functions alongside an administrative body that reviews the implementation of the agreement within an Advisory Committee. ${ }^{53}$ EUROBATS is the only subsidiary to have formally extended its original institutional structure to create a forum for technical review. ${ }^{54}$ The MOUs generally receive scientific advice from the $\mathrm{CMS}^{55}$ but have increasingly 'adopted' existing technical committees from other bodies ${ }^{56}$ or NGOs. ${ }^{57}$

The CBD operates a Subsidiary Body of Scientific, Technical and Technological Advice (SBSTTA), charged with providing 'timely advice relating to the implementation of the CBD. ${ }^{58}$ The SBSTTA is complemented by a clearing-house mechanism, which was established at the first COP as mandated by Article 18(3), 'to promote and facilitate technical and scientific cooperation.' Meanwhile, CITES no longer operates a single unified scientific forum. Its original Technical Expert Committee_- previously established at the second COPwas considered too unwieldy and was accordingly disbanded in 1987 in favour of separate specialist committees. ${ }^{59}$ The Animals and Plants Committees exercise an advisory role in reviewing proposed amendments to the CITES appendices as well as other trade-related issues, and they can undertake periodic reviews of CITES-listed species. ${ }^{60}$ These committees may issue recommendations to the COP and to the parties themselves, for which non-compliance may be referred back to the convention institutions.

Unlike the other BRCs, the Ramsar Convention did not initially provide for a designated technical body and its celebrated Scientific and Technical Review Panel (STRP) emerged at a comparatively advanced stage in the convention's

51 This was seemingly designed to prevent engagement with 'issues that were scientifically interesting but politically undesirable.' S. Lyster, The Convention on the Conservation of Migratory Species of Wild Animals (The 'Bonn Convention')' 29 Natural Resources J 979 at 995 (1989).

52 ACCOBAMS, supra note 29, Article VIII (establishing a Scientific Committee); AEWA, supra note 28, Article VII (establishing a Technical Committee); Gorilla Agreement, supra note 28, Article VI (establishing a Technical Committee).

53 ACAP, supra note 28, Article IX; ASCOBANS, supra note 29 at para. 6.

54 EUROBATS, supra note 28, Resolution 5.8: Establishment of a Standing Committee of the Agreement.

55 With the exception of the Migratory Sharks MOU, which establishes an advisory committee reminiscent of the more formalized CMS agreements (see section 7 of the MOU).

56 Mediterranean Monk Seal MOU, supra note 32 at para. 4 (nominating the Atlantic Seal Working Group); West African Elephants MOU, supra note 32 at para. 4 (nominating the IUCN African Elephant Specialist Group).

57 Birdlife International provides technical assistance to the Great Bustard and Aquatic Warbler MOUs, supra note 32, while the World Wildlife Fund undertakes these responsibilities in respect of the Bukhara Deer MOU, supra note 32.

58 CBD, supra note 8, Article 25(1).

59 The Plants Committee, Animals Committees, Nomenclature Committee, and Identificational Manuals Committee replaced this overarching body.

60 CITES, supra note 6, Resolution Conf. 11.1: Establishment of Committees, Annex 2 (2000). 
tenure. ${ }^{61}$ The STRP has nonetheless become a key institution within the Ramsar Convention's structure and has a strong role to play in developing scientific policies in conjunction with other bodies. ${ }^{62}$ Meanwhile, technical advice is provided to the World Heritage Convention within its executive framework, and expert guidance may also be co-opted from existing specialist organizations. ${ }^{63}$ Likewise, the ITPGRFA has eschewed the 'premature' development of a permanent advisory forum, instead preferring the use of 'ad hoc technical bodies with focused, specialized and outcome-orientated terms of reference' for the mid-term future. ${ }^{64}$

\section{The BRCs and the Scope for Synergy Agreements}

As outlined later in this article, the BRCs have generally framed their synergy arrangements by concluding various instruments of co-operation between themselves and other bodies. The development of relationships between regimes at a multilateral level is not a new phenomenon, although the practice of MEAs has made such arrangements relatively ubiquitous in recent years. This has, however, generated a degree of legal complication concerning the format and validity of co-operative instruments between the BRCs.

For orthodox IGOs, such as UNESCO, this is a relatively uncomplicated affair. The basis for co-operation with other bodies may be pursued through the express permission of their treaties or by attribution through the doctrine of implied powers. The latter foundation permits such bodies to act in the spirit of their mandates and undertake tasks that, while not explicitly referenced within their constituent treaties, are nonetheless fundamental to their effective functioning. This principle was famously established by the International Court of Justice through Reparation for Injuries Suffered in the Service of the United Nations, ${ }^{65}$ Effects of Awards Made by the UN Administrative

61 Ramsar Convention, supra note 4, Resolution 5.5 on the Establishment of a Scientific and Technical Review Panel (1993).

62 Reinforced most recently by Ramsar Convention, supra note 4. Resolution XI.16 on ensuring efficient delivery of scientific and technical advice and support to the Convention; Resolution XI.17 on future implementation of scientific and technical aspects of the Convention for 2013-2015; and Resolution XI.18 on adjustments to the modus operandi of the Scientific and Technical Review Panel (STRP) for the 2012-2015 triennium (2012).

63 World Heritage Convention, supra note 5, Article 14(2), citing the Rome Centre, the International Council on Monuments and Sites (ICOMOS) and the IUCN as providing services that the director-general may utilize 'to the fullest extent possible.' This process is considered to have a valuable role in depoliticizing decision making under the auspices of the World Heritage Convention. Vrdoljak, supra note 43 at 260.

64 Food and Agriculture Organization (FAO), Report of the Second Session of the Governing Body of the International Treaty on Plant Genetic Resources for Food and Agriculture, Doc. IT/GB-2/07/ Report (2007) at 15.

65 Reparation for Injuries Suffered in the Service of the United Nations, [1949] ICJ Rep 174 at 182-83 (noting that ' $[\mathrm{u}]$ nder international law, the Organisation must be deemed to have those powers 
Tribunal, ${ }^{66}$ and Certain Expenses of the United Nations (Article 17, Paragraph 2 of the Charter), ${ }^{67}$ which echo earlier judgments of the Permanent Court of International Justice. ${ }^{68}$ Although the sustained use of implied powers can be problematic, especially where treaty organs seek to explore contentious new territories, ${ }^{69}$ the development of co-operative agreements nonetheless remains a generally accepted aspect of such practices. ${ }^{70}$

MEAs are clearly_and deliberately_not IGOs in the traditional sense. ${ }^{71}$ Nevertheless, given the institutional similarities between them, these bodies are widely considered to 'fulfil the necessary criteria for an IGO and would thus aspire to the application of international institutional law.' 72 Accordingly, the BRCs would seem able to pursue collaborative arrangements to at least some degree. Thus far, instruments of co-operation between the BRCs have been concluded in the form of MOUs or memoranda of co-operation (MOCs). Whatever the nomenclature, it is clear that such instruments are generally intended to be non-binding, although as outlined in the following sections they have been highly influential in framing institutional activities and policies.

Such MOUs are generally concluded between the Secretariats, at the behest of the COP, which has raised questions over the precise legal basis for such arrangements. ${ }^{73}$ Secretariats are rarely endowed with independent legal personality by the constituent treaty, an issue that has created difficulties in discharging even the most mundane practical functions. ${ }^{74}$ While MEAs are generally deemed to hold legal personality-again, by analogy to practices within the IGOs $^{75}$ - this juridical character is essentially concentrated within the COP. This arrangement creates a paradoxical modus operandi: the COP enjoys clear legal personality, yet the treaty's global ambassador remains its Secretariat. Legal personality can be bestowed upon the Secretariat by the constituent

which, though not expressly provided in the Charter, are conferred upon it by necessary implication as being essential to the performance of its duties' (at 182)).

66 Effects of Awards Made by the UN Administrative Tribunal, [1954] ICJ Rep 47 at 56-60.

67 Certain Expenses of the United Nations (Article 17, Paragraph 2 of the Charter), [1962] ICJ Rep 151 at $166-70$.

68 Jurisdiction of the European Commission of the Danube between Galatz and Braila, [1926] Publ. PCIJ, Series B, No. 14 at 64; Interpretation of the Greco-Turkish Agreement of 1 December 1926, [1928] Publ. PCIJ, Series B, No. 16 at 19.

69 Notably within the International Whaling Commission (IWC) to refine practices on scientific research and Aboriginal subsistence hunting. M. Bowman, 'Normalizing' the International Convention for the Regulation of Whaling 29 Michigan J Int'1 L 293 at 350 (2008).

70 M.A. Young, Trading Fish, Saving Fish: The Interaction between Regimes in International Law, at 155 (2011).

71 Churchill and Ulfstein, supra note 11 at 629-31.

72 Ibid. at 633.

73 Young, supra note 70 at 157.

74 For an illuminating account of these difficulties, see Desai, supra note 13 at 133-70; see also M.A. Young, Regime Interaction in Creating, Implementing and Enforcing International Law, in M.A. Young (ed.), Regime Interaction in International Law: Facing Fragmentation, at 85-110 (2012).

75 Churchill and Ulfstein, supra note 11 at 655. 
treaty, as is the position under the $\mathrm{CBD},{ }^{76}$ or through explicit conferral by the $\mathrm{COP}$, as is the case, for example, with the $\mathrm{CMS}^{77}$ and, prospectively, the Ramsar Convention. ${ }^{78}$ Moreover, the requisite capacity to conclude MOUs has been 'assumed' by Secretariats to which the COP has been more circumspect. ${ }^{79}$ With little meaningful challenge to the legitimacy of such practices under CITES, competence to elaborate non-binding instruments of co-operation by the Secretariats may be presumed to exist in the absence of an express contrary position. The one exception among the BRCs is the World Heritage Centre, which remains wedded to UNESCO's general administrative structure and lacks the autonomy of other Secretariats within the biodiversity network. Although considered a 'legal aberration' in some quarters, this position has not adversely affected the elaboration of synergy arrangements. ${ }^{80}$ As an IGO, UNESCO is unquestionably competent to establish collaborative arrangements with other fora-and has indeed engaged with numerous multilateral bodies.

Questions remain whether MEA Secretariats may conclude formal treaties to address their relations, in the same way as IGOs. A modest degree of treaty-making power has been demonstrated in the specific context of headquarters arrangements with the host state or organization. ${ }^{81}$ Without downplaying the fundamental importance of this question to ongoing institutional practices, it nonetheless appears that treaty-making competence is unnecessary in advancing synergy arrangements. As demonstrated in the third part of this article, effective synergies may be cultivated through MOUs, without the need for a formal treaty. Indeed, MOU-based approaches have consistently been the favoured method of establishing collaborative practices between various multilateral biodiversity actors. There has been little meaningful appetite to frame co-operation through more formalized treaty structures, and, indeed, it is questionable whether more legalistic arrangements would ultimately deliver additional improvements in synergy practices.

\section{Synergy Arrangements and the Law of Treaties}

Traditionally, international law has framed interactions between treaties through the language of conflict resolution or the elaboration of normative hierarchies. Yet it is becoming increasingly clear, especially in the context of natural

76 CBD, supra note 8, Article 24(d).

77 CMS, supra note 7, Resolution 6.9: Juridical Personality of, and Headquarters Agreement for, the Convention Secretariat (1999).

78 Ramsar Convention, supra note 4, Resolution X.5 on Facilitating the Work of the Ramsar Convention and Its Secretariat (1994). See also Report on the Legal Personality of the Ramsar Secretariat, Ramsar COP-10 Doc. 35 (2008). COP-11 to the Ramsar Convention in July 2012 saw the appointment of an ad hoc legal advisor to address this and other allied issues. Legal Advisor for Ramsar COP11, Ramsar COP-11, Doc. 37 (2012).

79 Legal Personality of the Convention and the Secretariat, Doc. SC54 Doc. 8 (2006). Nevertheless, the precise root of this legal personality remains uncertain. See Young, supra note 70 at 157.

80 Desai, supra note 13 at 152.

81 Ibid. at $164-70$. 
resources and environmental protection, that such a model is unsuitable for treaties that seek to supplement rather than supplant each other. Although most BRCs contain conflict clauses to address their relationship with alternative treaties upon their activities, such provisions have ultimately shed little light upon their purported interaction with each other. Moreover, little guidance is forthcoming from the general law of treaties, which has tended to focus more on the role of successive treaties that are clearly intended to replace existing accords, as opposed to facilitating synergies between distinct treaties operating within broadly similar spheres of activity. The relationship between these bodies appears therefore to be a more subtle and less regimented phenomenon than is currently recognized and accommodated within the general international law of treaties.

In chronological terms, the Ramsar Convention contained no specific provisions governing its application to other treaties, lacking a specific conflict clause and being primarily concerned with establishing its guiding principles and constituent institutions. The World Heritage Convention incorporated a limited conflict clause, addressing the position (to date, hypothetical) regarding future treaties on world heritage that may be adopted under the specific auspices of UNESCO. ${ }^{82}$ This provision lies alongside a general commitment to co-operate with international and national governmental and non-governmental bodies 'having objectives similar to those of' the committee. ${ }^{83}$ The ITPGRFA also eschewed a specific conflict clause, although multiple references throughout the text envisage a close correlation with CBD commitments and practices in developing key policies. ${ }^{84}$

In the 1970s, savings clauses were incorporated into CITES and the CMS to avoid potential difficulties with the burgeoning codification of the law of the sea, ${ }^{85}$ which were a relatively common addition to treaties with a marine application at the material time. ${ }^{86}$ Accordingly, the CMS has incorporated a relatively non-contentious provision to this effect, ${ }^{87}$ alongside a general commitment to 'in no way affect the rights or obligations of any Party deriving from any

\footnotetext{
82 World Heritage Convention, supra note 5, Article 37(2).

83 Ibid., Article 13(7).

84 See especially ITPGRFA, supra note 9, Articles 17-20. Moreover, the objectives of the ITPGRFA are to be realized 'in harmony with the Convention on Biological Diversity' (Article 1.1).

85 CITES, supra note 6, subsequently clarified its interpretation of the 'marine environment not under the jurisdiction of any State' with specific reference to the 1982 UN Convention on the Law of the Sea, 1883 UNTS 396 [UNCLOS], Resolution Conf. 14.6: Introduction from the Sea (2007). This formulation nonetheless remains controversial with parties that have rejected the 1982 convention.

86 C. Redgwell, From Permission to Prohibition: The 1982 Convention on the Law of the Sea and the Protection of the Marine Environment, in D. Freestone, R. Barnes, and D. Ong (eds.), The Law of the Sea: Progress and Prospects, at 184 (2006).

87 CMS, supra note 7, Article XII(1). This provision is identical to Article XIV(6) of CITES, a clause that has been considered to be 'well nigh bereft of meaning.' E. Franckx, The Protection of Biodiversity and Fisheries Management: Issues Raised by the Relationship between CITES and LOSC, in Freestone, Barnes, and Ong, supra note 86 at 225.
} 
existing treaty, convention or Agreement.' 88 This provision has given rise to comparatively little debate beyond the potential application of the CMS to whale stocks, with the inter-relationship with the IWC having ultimately proven to be harmonious. ${ }^{89}$

A more extensive conflict clause is incorporated into Article XIV of CITES, which provoked considerable debate during the treaty negotiations. CITES advances two particular provisions that are framed in deferential terms towards alternative fora. Under Article XIV(2), CITES mandates a general compatibility with other treaties, in a similar vein to the CMS. Most strikingly, however, Article XIV(4) addresses pre-existing regimes under which 'protection is afforded to marine species included in Appendix II.' Under these circumstances, a CITES party that is also a party to such a treaty 'shall be relieved of the obligations imposed on it under the provisions of the present Convention with respect to trade in specimens of species included in Appendix II that are taken by ships registered in that State and in accordance with the provisions of such other treaty, convention or international agreement.'

This unique position in the marine context is a product of the drafting process, in which the application of the emerging treaty to commercially exploited marine species was a matter of sustained controversy. A number of negotiating parties expressed concerns over the scope for regulatory overlaps and conflicts with fisheries and, especially, with whaling concerns. Some delegations supported the insertion of a further appendix to CITES, listing pertinent multilateral agreements, but this proposed adjunct to the convention was ultimately omitted from the final text. ${ }^{90}$ This provision remains subject to considerable uncertainty. As Margaret A. Young observes, it would appear to apply solely to pre-1975 bodies that advance the (undefined) goal of the 'protection' of marine species, prompting confusion over which regimes are caught by this formulation. ${ }^{91}$ This position has therefore remained a source of ongoing debate as CITES has sought to frame its precise relationship with the IWC and in its increasing engagement with fisheries issues.

Further difficulties have arisen in the case of the CBD, which has advanced an expansive and idiosyncratic conflict clause. Article 22 provides:

(1) The provisions of this Convention shall not affect the rights and obligations of any Contracting Party deriving from any existing international

88 CMS, supra note 7, Article XII(2).

89 A. Gillespie, Whaling Diplomacy: Defining Issues in International Environmental Law, at 332-34 (2005).

90 Franckx, supra note 87 at 224.

91 Young, supra note 70 at 66. 
agreement, except where the exercise of those rights and obligations would cause a serious damage or threat to biological diversity.

(2) Contracting Parties shall implement this Convention with respect to the marine environment consistently with the rights and obligations of States under the law of the sea.

The elaboration of a conflict clause in the first instance, and the form in which it was ultimately expressed, were controversial issues during the negotiation of the CBD. Numerous parties considered such a provision superfluous in the first instance, while others viewed the end product as highly unsatisfactory. ${ }^{92}$ The wording of Article 22, which is considered 'unusual and can lead to a de facto precedence of the Convention on Biological Diversity in respect to other instruments,' has prompted the submission of an array of interpretive statements. ${ }^{93}$ As with Article XIV(4) of CITES, there remains considerable uncertainty regarding the treaties to which Article 22 purports to apply. Moreover, the precise threshold of potentially harmful activities endorsed by such treaties is also vague- the concept of 'serious' threats and damage is perhaps inherently indefinable. Accordingly, as Martti Koskenniemi wryly surmises, '[i]t seems unclear what is in fact being overridden by what in these provisions.' 94

Ambiguity surrounds the extent to which Article 22 might be considered to modify existing and future treaties in order to promote biodiversity conservation. Thus far, and perhaps unsurprisingly given the additional qualification advanced under Article 22(2), this debate has primarily concentrated on the inter-relationship between the CBD and the UN Convention on the Law of the Sea (UNCLOS). ${ }^{95}$ UNCLOS is not explicitly referenced within this formulation, largely for 'reasons of compromise aimed at ensuring consensus' that were contemporaneous to the drafting of the CBD, whereby the 1982 convention had yet to enter into force and remained controversial within a considerable number of states. ${ }^{96}$ Two separate conflict clauses within UNCLOS have proven to be significant in mapping the impact of the CBD. Article 311(3) permits the conclusion of instruments suspending the provisions of UNCLOS, provided that

92 M. Chandler, The Biodiversity Convention: Selected Issues of Interest to the International Lawyer 4 Colorado J Int'l Envt'1 L \& Pol'y 141 at 149 (1993).

93 R. Wolfrum and N. Matz, The Interplay of the United Nations Convention on the Law of the Sea and the Convention on Biological Diversity 4 Max Planck Y UN L 445 at 475 (2000).

94 M. Koskenniemi, Fragmentation of International Law: Difficulties Arising from the Diversification and Expansion of International Law. Report of the Study Group of the International Law Commission, at 137 (2006).

95 UNCLOS, supra note 85.

96 P. Birnie, The Framework for Conservation of Whales and Other Cetaceans as Components of Marine Biodiversity, in W.C.G. Burns and A. Gillespie (eds.), The Future of Cetaceans in a Changing World, at 107 (2003). 
such agreements do not relate to a provision derogation from which is incompatible with the effective execution of the object and purpose of this Convention, and provided further that such agreements shall not affect the application of the basic principles embodied herein, and that the provisions of such agreements do not affect the enjoyment by other States Parties of their rights or the performance of their obligations under this Convention.

Further illumination is to be found under Article 237, which operates without prejudice to present or future agreements relating to the marine environment, provided that these external obligations be applied 'in a manner consistent with the general principles and objectives of this Convention.'

The CBD has developed a growing portfolio of marine policies, pursued collectively under the 'Jakarta Mandate' established at its second COP. ${ }^{97}$ Thus far, key policies have included integrated coastal management, the development of protected areas, and an increasing focus on specific anthropogenic pressures upon the oceans. The CBD may therefore exercise a considerable influence over the modern interpretation by states of their rights and obligations prescribed under UNCLOS, especially in the context of Part XII of the latter treaty, addressing the marine environment. The CBD could provide a useful framework to strengthen national implementation of Part XII of UNCLOS, demonstrating that both treaties may be considered to be organic regimes capable of adapting to changing environmental concerns. The CBD may be envisaged to modify the broad regulation of maritime activities prescribed under UNCLOS in which biodiversity becomes threatened. Such considerations could potentially justify curtailing UNCLOS privileges through, for instance, imposing fishing restrictions or establishing marine protected areas. ${ }^{98}$ Conversely, Article 311(3) would guard against biodiversity considerations being used as a pretext by states to reverse central tenets of UNCLOS, including fundamental navigational rights and high seas freedoms, in implementing their CBD commitments. Again, however, there is relatively little understanding of the tipping-point by which rights and obligations prescribed under one regime may become sufficiently threatening as to merit ongoing modification by another. The precise inter-relationship of these principles therefore remains a delicate balancing act between the various institutions of the respective conventions and is likely to be elaborated more fully in future years as the CBD's marine policies mature further.

The rather odd formulation of Article 22 appears to have been replicated in a biodiversity context on only one subsequent occasion. Article XI(1) of Agreement on the Conservation of Cetaceans of the Black Sea, Mediterranean Sea and Contiguous Atlantic Area (ACCOBAMS) states that the agreement does

\footnotetext{
97 Decision II/10: Conservation and Sustainable Use of Marine and Coastal Biological Diversity (1995).

98 A. Boyle, Further Development of the Law of the Sea Convention: Mechanisms for Change 54 Int'1 \& Comp L Q 563 at 579 (2005).
} 
not affect the rights or obligations of any other party deriving from any existing instrument 'except where the exercise of these rights or obligations would threaten the conservation of cetaceans.' This provision has already demonstrated an ability to create mischief for the agreement's relationship with other bodies, notably the European Union (EU). The EU shares a number of mutual members and has adopted occasional, yet significant, divergent policies regarding marine mammals. In particular, the EU has required fishing vessels of over twelve metres in length to fix acoustic deterrent devices, or 'pingers,' to their nets in order to warn cetaceans of their presence. ${ }^{99}$ In contrast, both the ACCOBAMS Scientific Committee ${ }^{100}$ and the $\mathrm{MOP}^{101}$ have been reluctant to endorse the widespread use of such devices, citing concerns over noise habituation, habitat displacement, and even physical injury to cetaceans from pingers. ${ }^{102}$

These concerns are arguably caught by Article XI(1) on a strict construction of this provision. Such a position would have significant implications for those parties that are also EU member states, which could face infringement proceedings if they applied this conflict clause rigidly. In practice, it appears that ACCOBAMS has chosen the path of least resistance, not least given the uncertain legal strength of its policies on this issue, ${ }^{103}$ and it has subsequently diluted its firmer rhetoric against acoustic deterrent devices. Indeed, its most recent pronouncement on pingers has advised 'great care' in testing these appliances prior to their widespread introduction as advocated by the $\mathrm{EU}^{104}$ - a position that would appear to be in accordance with the agreement's stated commitment towards applying the precautionary principle. ${ }^{105}$ Accordingly, it appears unlikely that Article XI(1) will be invoked in any meaningful context in the near future, with the MOP ultimately proving more conciliatory in practice than this provision might suggest, especially in its dealings with the EU.

As outlined earlier, conflict clauses in treaties of global application have been generally drafted in a vague and open-ended manner. The reasons are fairly obvious: even the most prescient of drafters are unable to predict future changes to the international normative landscape. ${ }^{106}$ This position contrasts with

99 EC Council Regulation 812/2004 Laying Down Measures Concerning Incidental Catches of Cetaceans in Fisheries and Amending Regulation 88/98, [2004] OJ L171/1 (26 April 2004).

100 Recommendation SC1.1 on the Use of Acoustic Devices (2002); Recommendation SC2.1: Guidelines for the Use of Acoustic Deterrent Devices-A Way Forward (2003); Recommendation SC4.12: Acoustic Harassment Devices (2006).

101 Resolution 3.12; By-Catch, Competitive Interactions and Acoustic Devices (2007); Resolution

4.9: Fisheries Interactions with Cetaceans (2010).

102 Resolution 2.12: Guidelines for the Use of Acoustic Deterrent Devices (2004). On this issue generally, see R. Caddell, Biodiversity Loss and the Prospects for International Cooperation: EU Law and the Conservation of Migratory Species of Wild Animals 8 Y Eur. Envt'1 L 219, at 251-54 (2008).

103 R. Churchill and D. Owen, The EC Common Fisheries Policy, at 335 (2010).

104 Resolution 4.9, supra note 101.

105 ACCOBAMS, supra note 29, Article II(4).

106 See P. Birnie, Are Twentieth-Century Marine Conservation Conventions Adaptable to Twenty-First Century Goals and Principles? 12 Int'1 J Marine \& Coastal L 307 (1997). 
instruments that have a more regional application, which may often have specific interactions in mind. A striking example is again presented by ACCOBAMS, which constitutes an ambitious project to link two distinct marine regions that had not previously been subject to overarching regulatory oversight for biodiversity concerns. Uniquely, in seeking to engage with pre-existing regional institutions, the organizational framework of ACCOBAMS includes specific roles for the Convention for the Protection of the Mediterranean Sea against Pollution (Barcelona Convention) ${ }^{107}$ and the Convention on the Protection of the Black Sea against Pollution (Bucharest Convention). ${ }^{108}$ The agreement envisages the establishment of sub-regional co-ordination units to implement conservation priorities and collect relevant data within the Mediterranean and Black Sea regions respectively. ${ }^{109}$ Accordingly, the Regional Activities Centre for Specially Protected Areas of the Barcelona Convention has been appointed as the sub-regional co-ordination unit for the Mediterranean Sea and contiguous Atlantic area, ${ }^{110}$ while the Black Sea Commission has assumed this mantle for the Black Sea. ${ }^{111}$ In this way, the agreement has been able to engender a spirit of co-operation with relevant multilateral agreements from a preliminary stage in its operations. Likewise, the 1994 Lusaka Agreement on Cooperative Enforcement Operations Directed at Legal Trade in Wild Flora and Fauna ${ }^{112}$ considers its role with primary reference to CITES commitments. ${ }^{113}$ Furthermore, in one of the clearer examples of a conflict clause, the 1980 Convention on the Conservation of Antarctic Marine Living Resources (CAMLR Convention) ${ }^{114}$ frames its responsibilities as being subordinate both to those of the International Convention for the Regulation of Whaling (Whaling Convention) ${ }^{115}$ and the 1972 Convention for the Conservation of Antarctic Seals, ${ }^{116}$ as well as the 1959 Antarctic Treaty. ${ }^{117}$

Little guidance is prescribed under the 1969 Vienna Convention on the Law of Treaties (Vienna Convention) to address the specific question of synergies

107 Convention for the Protection of the Marine Environment and the Coastal Region of the Mediterranean, 1102 UNTS 27.

108 Convention on the Protection of the Black Sea against Pollution, 1764 UNTS 3.

109 Ibid., Article V(1).

110 Resolution 1.4: Establishment of the Subregional Co-ordination Unit for the Mediterranean Sea and the Contiguous Atlantic Area (2002).

111 Resolution 1.5: Establishment of the Subregional Co-ordination Unit for the Black Sea (2002).

112 Lusaka Agreement on Cooperative Enforcement Operations Directed at Legal Trade in Wild Flora and Fauna, 1950 UNTS 35.

113 Ibid., Article 4(9).

114 Convention on the Conservation of Antarctic Marine Living Resources, 1329 UNTS 47 [CAMLR Convention].

115 International Convention for the Regulation of Whaling, 161 UNTS 72 [Whaling Convention].

116 Convention for the Conservation of Antarctic Seals, 180 UNTS 175. Article VI of the CAMLR Convention states, '[n]othing in this Convention shall derogate from the rights and obligations of Contracting Parties under the International Convention for the Regulation of Whaling and the Convention for the Conservation of Antarctic Seals.'

117 Antarctic Treaty, 402 UNTS 71; see Article V of the CAMLR Convention, supra note 114. 
between conventions. ${ }^{118}$ With the exception of the Charter of the United Nations, ${ }^{119}$ distinct treaties do not generally form a natural hierarchy, ${ }^{120}$ a theme reinforced within the ITPGRFA preamble. ${ }^{121}$ Thus far, in the biodiversity context, the relationship between treaties has overwhelmingly been one of partnership, not purported dominance. Indeed, attempts to establish hierarchical arrangements between these treaties have rarely improved the working relationship between them. This position has only been seriously asserted in the specific context of whaling, where the boundaries of responsibility between CITES and the IWC have raised forceful debate. Although the IWC ${ }^{122}$ and CITES ${ }^{123}$ have repeatedly pledged to work together effectively, friction has been generated by efforts to undermine the IWC's global moratorium on commercial whaling by mutual parties seeking to downgrade the protection accorded to particular species under the trade convention, much to the chagrin of both regimes. CITES subsequently declared that '[n]o periodic review of any great whale... should occur while the moratorium by the International Whaling Commission is in place.' ${ }^{124}$

Given these concerns, it has been advocated that the two bodies should operate on a hierarchical basis, founded primarily on the longevity and specificity of the Whaling Convention, to which CITES ought to defer to the perceived primacy of the whaling regime. ${ }^{125}$ The IWC has previously sought to reaffirm its position as 'the universally recognised competent international organisation for the management of whale stocks' in its dealings with CITES. ${ }^{126}$ Nevertheless, primacy arguments have been frequently tinged with considerable realpolitik in the whaling debate, espoused 'by both proponents and by opponents of whaling, for different tactical reasons.' ${ }^{127}$ Instead, CITES practice suggests that its

\footnotetext{
118 Vienna Convention on the Law of Treaties, 1155 UNTS 331 [Vienna Convention].

119 Charter of the United Nations, 1 UNTS 16 [UN Charter].

120 Article 103 of the UN Charter, ibid., as reinforced by Article 30 of the Vienna Convention, supra note 118 .

121 Observing that while the ITPGRFA, supra note 9, does not affect the pre-existing rights and obligations of parties, it 'is not intended to create a hierarchy between this Treaty and other international agreements.'

122 Resolution 1994-7: International Trade in Whale Meat and Products (1994); Resolution 1995-6: Improving Mechanisms to Prevent Illegal Trade in Whale Meat (1995); Resolution 1996-3 on Improving Mechanisms to Restrict Trade and Prevent Illegal Trade in Whale Meat (1996); Resolution 1999-6 on Cooperation between the IWC and CITES (1999); Resolution 2007-4 on CITES (2007).

123 Resolution Conf. 2.7: Relationship with the International Whaling Commission (1979); Resolution Conf. 3.13: Trade in Whale Products (1981); Resolution Conf. 9.12: Illegal Trade in Whale Meat (1994); Resolution Conf. 11.4: Conservation of Cetaceans, Trade in Cetacean Specimens and the Relationship with the International Whaling Commission (2000).

124 Decision 14.81: Great Whales (2007).

125 A. Gillespie, Forum Shopping in International Environmental Law: The IWC, CITES and the Management of Cetaceans 33 Ocean Development \& Int'1 L. 17 at 31 (2002).

126 Resolution 1999-6, supra note 122.

127 P.H. Sand, Japan's 'Research Whaling' in the Antarctic Southern Ocean and the North Pacific Ocean in the Face of the Endangered Species Convention (CITES) 17 RECIEL 56 at 61 (2008).
} 
strategy towards whales is founded on a rather more egalitarian basis than an unconditional endorsement of IWC policies. In framing its policy against the downlisting of Appendix I whales, CITES is required to consider 'the views, if any, of intergovernmental bodies with competence for the management of the species concerned.' ${ }^{128}$ This arrangement appears to be based less on deference to the presumed primacy of the Whaling Convention than on a simple application of the relevant CITES criteria. Tellingly, perhaps, a hint as to the true nature of primacy arrangements may have been subsequently established by the organizations themselves. The IWC most recently observed that 'CITES recognises the IWC's Scientific Committee as the universally recognised international institution with international expertise to review and evaluate the status of the world's whale stocks, ${ }^{129}$ while CITES Resolution 11.4 correspondingly recognizes the IWC as 'the major source of information' on global whale stocks. The explicit recognition by CITES of the scientific pre-eminence of the IWC concerning a relatively small number of marine species is accordingly very different to a formal acceptance of a hierarchical arrangement between the two regimes.

On an allied theme, the Vienna Convention does establish a clear position concerning successive treaties relating to the same subject matter in which the later instrument prevails, through the lex posterior derogat legi priori rule. ${ }^{130}$ Nevertheless, it is highly questionable whether the rules on successive treaties are applicable to purported synergies between the BRCs. During the CBD negotiations, Article 30 of the Vienna Convention was considered by a number of delegations to negate the need for a (then) draft conflict clause, which would eventually become Article 22. The Vienna Convention presents a useful framework for addressing treaties that were clearly intended to supersede earlier accords, whereby Article 30 mandates the application of the later treaty between those that have ratified it. However, it is difficult to argue that the BRCs can be considered to be successive treaties to each other, notwithstanding their shared application to aspects of nature conservation. Indeed, this position was explicitly rejected during the $\mathrm{CBD}$ negotiations, in which the parties were unable to identify the precise range of treaties that engaged the 'same subject matter.' 131

Instead, the incorporation of Article 22 represents a de facto acknowledgement that the CBD is not a successive treaty to the pre-existing instruments, which remain individualized structures comprising specific components of international nature conservation law. They are mutually supportive regimes, rather than prototype treaties, which, having served their purpose, ought to be extinguished by a later codifying hierarchy. Despite the global leadership presented by the CBD, it does not operate on a hierarchical basis, opting instead to designate more specialist treaties as 'lead partners' or to form practical working

128 Resolution Conf. 11.4, supra note 123, Criterion (k).

129 Resolution 2007-4, supra note 122 [emphasis added].

130 Vienna Convention, supra note 118, Article 30.

131 Chandler, supra note 92 at 149. 
arrangements with other organizations, as opposed to asserting normative dominance. While the approach of Article 30 and similar rules of construction, which have been utilized to bring order to an increasingly fragmented system of international law, ${ }^{132}$ retain enduring interpretive vitality, they are largely inappropriate to establish the precise inter-relationship between the BRCs. Article 30 generally offers little practical guidance concerning interactions between specialist regimes. Moreover, the fragmentation debate has often focused on the role of dispute resolution, whereas the BRCs seek not to resolve inherent conflicts but, rather, to improve collaborative working practices in discharging their respective mandates.

The model of co-operation applied by the BRCs - and, indeed, most MEAsis therefore to establish strategic alignments between their various institutions to develop unified conservation policies in areas of mutual interest and thus avoid confusion, duplication, and wastage of efforts. The precise mechanics of such arrangements, and their scope for creating clear and effective synergies, is therefore primarily determined at the executive and administrative levels of the treaties in question.

\section{TRENDS AND DEVELOPMENTS IN SYNERGY ARRANGEMENTS}

Since the mid-1990s, where the first tentative linkage arrangements were established, inter-treaty co-operation has tended to encompass two broad formats. Both models offer differing opportunities for interaction, yet they have also entailed significant practical difficulties, which have required considerable policy adjustments. First, on a collective level, the BRCs have aligned themselves within a CBD-sponsored forum termed the Biodiversity Liasion Group (BLG), with the general aim of improving common administrative practices and developing issues of mutual interest. The BLG, which operates at the executive level, is complemented by a broadly parallel organization comprising the technical bodies of the leading biodiversity treaties, which has sought to improve scientific co-operation and co-ordination between these regimes. Second, and more disparately, individual BRCs have also developed working relationships between themselves on matters of common concern. These arrangements have been typically developed through MOUs, which have subsequently spawned joint initiatives, work programs, and thematic policies, with varying degrees of success and efficiency.

\section{Collective Approaches}

On a collective basis, interactions have been developed at the executive level to address crosscutting management issues. Considerable faith has been placed in improving institutional coherence as a primary mechanism for mitigating the

132 Koskenniemi, supra note 94. 
increasing fragmentation of international environmental governance. ${ }^{133}$ The 'clustering' of allied regimes, through combined meetings, co-located institutions, and more streamlined administrative practices has been considered a potentially effective means of addressing some of the more pervasive problems associated with treaty congestion. ${ }^{134}$ The BRCs accordingly present an illuminating case study of the benefits and challenges of this policy.

Thus far, executive synergies have been pursued at both the Secretariat and the scientific/technical levels, with somewhat mixed results. Co-ordination between Secretariats through the BLG has perhaps generated rather more in the way of rhetoric than results in improving cross-institutional practices. In contrast, scientific co-operation on both a collective and bilateral level has demonstrated a clearer scope to advance practical synergies between the BRCs.

In 2004, the CBD established the BLG between CITES, the Ramsar Convention, the CMS, and the World Heritage Convention 'to enhance coherence and cooperation in their implementation,' ${ }^{135}$ which was expanded in 2006 to include the ITPGRFA. ${ }^{136}$ The BLG is broadly modelled on the Joint Liaison Group (JLG), a similar initiative launched in 2001 between the CBD and the two other Rio conventions, the UN Convention to Combat Desertification in Countries Experiencing Serious Drought and/or Desertification, Particularly in Africa ${ }^{137}$ and the UN Framework Convention on Climate Change. ${ }^{138}$ The BLG was inaugurated shortly after COP-7 to the CBD, and it provides a forum for executive staff to elaborate overarching policy priorities and identify further grounds for institutional synergies. Group meetings rotate between the various conventions and, where possible, dovetail with COPs or other major events.

Given the overarching priorities at the material time, the early focus of the BLG unsurprisingly concerned the pursuit of the 2010 biodiversity loss target, ${ }^{139}$ alongside contributions towards a nascent Global Partnership on Biodiversity, which was sponsored through the CBD. ${ }^{140}$ Subsequently, there has been a steady accretion of topics to the BLG agenda, derived both from the group's individual meetings and through steering from the CBD. ${ }^{141}$ With its managerial

133 B.H. Desai, Mapping the Future of International Environmental Governance 13 Y Int'1 Envt'1 L 43 (2000).

134 S. Oberthür, Clustering of Multilateral Environmental Agreements: Potentials and Limitations 2 Int'l Envt'l Agreements: Politics, L. \& Econ. 317 at 321-28 (2002).

135 Decision VII/26 on Strategic Plan for the Convention on Biological Diversity (2004).

136 Decision VIII/16 on Cooperation with Other Conventions and International Organizations and Initiatives (2006).

137 UN Convention to Combat Desertification in Countries Experiencing Serious Drought and/or Desertification, Particularly in Africa, 1954 UNTS 3.

138 UN Framework Convention on Climate Change, 1771 UNTS 107.

139 Decision VII/26, supra note 135 , at para. 11.

140 Report of the Second Meeting of the Liaison Group of Biodiversity-related Conventions Doc. BLG-2-Rep-Final (2004) at 2.

141 See Decision IX/27 on Cooperation among Multilateral Environmental Agreements and Other Organizations (2008); Decision X/20 on Cooperation with Other Conventions and International Organisations and Initiatives (2010). 
constitution, the BLG would appear to be best placed to address issues of crosscutting administrative concern between the BRCs, especially the lack of uniformity in reporting systems. This issue is discussed more fully in the fourth section of this article. However, despite a number of meetings and general discussions, the BLG appears no closer to a pragmatic solution to this issue than at its inception.

Otherwise, beyond general discussions of the desirability of harmonizing reporting systems, considerable attention has been focused on knowledge management, with the BLG keen to improve data exchange and to share models of good practice. This is an unsurprising priority, given that the MOUs concluded between the CBD and the other BRCs include the sharing of data and conservation experiences as a central feature. One practical BLG initiative that has borne fruit is the development by CITES of an interactive CD-Rom addressing the implementation of the Addis Ababa Principles and Guidelines, which encompasses guidance specific to each treaty and which has been welcomed by the parties as a helpful management tool. ${ }^{142}$ This project remains, however, perhaps the most tangible outcome from this forum to date.

Despite some encouraging initiatives regarding knowledge management, and notwithstanding the general desirability of a cost-effective forum for information exchange and collaborative dialogue, relatively few concrete developments have emerged from the direct auspices of the BLG. Indeed, in recent years, the group has experienced a series of operational difficulties, although there are signs of subtle, yet significant, reforms in the wake of the CBD's COP-10. Perhaps the most pressing issue remains a lack of structure within the BLG, which has tended to meet on an ad hoc basis with a fluctuating cast of participants. ${ }^{143}$ This shortcoming has been formally noted within its CBD sponsor, which has exhorted the BLG to meet more regularly. ${ }^{144}$

There are, however, signs that the BLG is moving to address these ongoing difficulties to establish a greater degree of coherence to its structure and working practices. At its most recent meeting, the BLG agreed that 'a more formal modus operandi' should be elaborated, ${ }^{145}$ which was duly adopted in September 2011. ${ }^{146}$ Mirroring developments on an individual treaty level, future work of the BLG will engage synergies on a national level, promote the implementation of the respective strategic plans, explore practical methods to implement respective COP decisions, and encourage a greater emphasis on publicity and outreach activities.

\footnotetext{
142 Report of the Sixth Meeting of the Liaison Group of Biodiversity-related Conventions, Doc. BLG-6-Rep-Final at 1 [Report of the Sixth Meeting of the Liaison Group].

143 Ibid. at 2.

144 Decision IX/27, supra note 141.

145 Report of the Special Meeting of the Liaison Group of Biodiversity-Related Conventions, Doc. BLG/8/2 (2011) at 1 [Report of the Special Meeting].

146 Modus Operandi for the Liaison Group of the Biodiversity-related Conventions, online: <http:// www.cbd.int/cooperation/doc/blg-modus-operandi-en.pdf $>$ [Modus Operandi].
} 
In the mid-term future, there appears to be scope to develop closer linkages with the JLG on issues of mutual interest. ${ }^{147}$ There would appear to be relatively little impediment to this approach, given that a number of the BRCs have developed co-operative working practices with the Desertification Convention and the UNFCCC. Moreover, this may prove helpful in establishing a more coherent structure for the BLG, with the JLG having recently taken steps to address similar problems. In April 2011, the JLG endorsed five guiding principles underpinning its common framework. These encompassed an acknowledgement that the JLG remains primarily a forum for information exchange, with particular emphasis on facilitating national implementation, respect for the differing mandates of the conventions, a commitment to decreasing bureaucracy, a need to reduce costs, especially for the parties, and for actions to be realistic in timescale and finance. ${ }^{148}$ Such principles have a clear resonance for the work of the BLG and were indeed echoed in recent attempts to formalize its structure. ${ }^{149}$

Beyond establishing a more regular forum for institutional dialogue and developing co-ordinated principles to guide the national implementation of treaty commitments, further integration of the BRCs through the BLG appears to be a relatively remote practical prospect. Thus far, the optimal model for executive inter-treaty co-operation is presented by the so-called 'chemical cluster,' comprising the 1989 Convention on the Control of Transboundary Movements of Hazardous Wastes and Their Disposal, ${ }^{150}$ the 1998 Convention on the Prior Informed Consent Procedure for Certain Hazardous Chemicals and Pesticides in International Trade, ${ }^{151}$ and the 2001 Stockholm Convention on Persistent Organic Pollutants. ${ }^{152}$ In March 2010, following the elaboration of a series of internal commitments towards improving synergies, the COPs of the three conventions convened a pioneering Simultaneous Extraordinary Meeting. The meeting culminated in the adoption of an omnibus decision pledging to establish joint services for financial and administrative support, legal issues, information technology, and information and resource mobilization, alongside the full synchronization of budget cycles, joint activities, and a process for review of these arrangements. ${ }^{153}$ Notwithstanding this landmark development, there has been

147 This has been advocated by the parties. Report of the Special Meeting, supra note 145. Moreover, Decision X/20, supra note 141, directed the CBD Secretariat to explore potential linkages between these two groups.

148 Report of the Eleventh Meeting of the Joint Liaison Group of the Rio Conventions, Doc. JLG-11-Report (2011) at 1-2.

149 Modus Operandi, supra note 146.

150 Convention on the Control of Transboundary Movements of Hazardous Wastes and Their Disposal, 1673 UNTS 57.

151 Convention on the Prior Informed Consent Procedure for Certain Hazardous Chemicals and Pesticides in International Trade, 2244 UNTS 337.

152 Stockholm Convention on Persistent Organic Pollutants, 2256 UNTS 119.

153 Report of the Simultaneous Extraordinary Meetings of the Conferences of the Parties to the Basel, Rotterdam and Stockholm Conventions, Doc. UNEP/FAO/CHW/RC/POPS/EXCOPS.1/8 (2010). 
little indication that the BLG is likely_or keen-to replicate these arrangements for the BRCs.

In addition to executive arrangements, synergies have also occurred on a scientific and technical level between the BRCs. In 2007, a forum for the chairs of the Scientific Advisory Boards (CSAB) of biodiversity-related conventions was inaugurated, growing largely out of the BLG. ${ }^{154}$ While the CSAB operates broadly in parallel to the BLG and the JLG, it works independently of these bodies, although it intends to track BLG developments 'more closely' in developing its future work program. ${ }^{155}$ Significantly, the CSAB adopts an expansive interpretation of 'biodiversity-related conventions,' encompassing a wider collective than the six BRCs. In marked contrast to the BLG, which has traditionally remained a closed forum, the CSAB is rather more representative of the scientific community servicing the BRCs and admits a variety of regional actors, UNEP bodies, and NGOs. ${ }^{156}$

Despite its relatively recent provenance, there are signs that the CSAB presents a clearer avenue for the development of meaningful collective practices between the BRCs, primarily because it engages matters with a unifying methodological resonance for all six treaties. Strategic priorities for the CSAB have mainly constituted examining areas of co-operation and translating scientific considerations into clear policies, alongside the identification of emerging issues with reference to problems and priorities within the individual scientific fora of the participating regimes. ${ }^{157}$ Thus far, such work has largely mirrored synergies between individual conventions in highlighting case studies and examples of good practice. Although seemingly mundane, in the scientific context such endeavours have an understated importance in driving synergistic arrangements and have contributed to a closer alignment on environmental impact assessments. ${ }^{158}$ They are also important in framing future policies on problematic issues such as climate change adaptation ${ }^{159}$ and emergency responses. Likewise,

154 Report of the Fifth Meeting of the Liaison Group of Biodiversity-related Conventions, Doc. BLG-4-Rep-Final (2006), at 5-6 [Report of the Fifth Meeting of the Liaison Group]; see also Decision VIII/16, supra note 136, calling for enhanced co-operation between scientific and technical bodies in addition to Secretariats.

155 Report of the Fourth Meeting of Chairs of Scientific Advisory Bodies of Biodiversity-related Conventions, Doc. UNEP/CBD/CSAB/4/2 (2011), at 9 [Report of the Fourth Meeting of Chairs].

156 Report of the Fourth Meeting of the Liaison Group of Biodiversity-related Conventions, Doc. BLG-4-Rep-Final (2005), at 3. A softer line was seemingly advanced by the Modus Operandi, which envisages the ad hoc involvement of other actors in future years, contingent upon universal agreement between the BLG members.

157 Report of the First Meeting of Chairs of Scientific Advisory Bodies of Biodiversity-Related Conventions, Doc. UNEP/CBD/CSAB/1/3 (2007), at 2.

158 Report of the Third Meeting of Chairs of Scientific Advisory Bodies of Biodiversity-Related Conventions, Doc. UNEP/CBD/CSAB/3/3 (2009), at 4 [Report of the Third Meeting of Chairs].

159 See A. Trouwborst, International Nature Conservation Law and the Adaptation of Biodiversity to Climate Change: A Mismatch? 21 J Envt'1 L 419 at 430-37 (2009); see also A. Trouwborst, Transboundary Wildlife Conservation in a Changing Climate: Adaptation of the Bonn Convention on Migratory Species and Its Daughter Instruments to Climate Change 4 Diversity 258 at 269-78 (2012). 
the development of guidance on ecosystem restoration-a pressing concern for all of the BRCs-will constitute a major area of future activity for the CSAB. ${ }^{160}$ Significantly, these meetings also promote an improved flow of data, which, despite numerous MOU commitments towards information sharing, often lack a formalized outlet for inter-treaty dissemination.

Most recently, two key collaborative policies have emerged for the CSAB. ${ }^{161}$ In the first instance, considerable attention has been accorded to implementing strategic plans in a more integrated and coherent manner as well as to providing scientific leadership for the further development of National Biodiversity Strategies and Action Plans (NBSAPs) mandated under the CBD. ${ }^{162}$ Second, following the difficulties identified by CITES and the CMS over scientific inconsistencies between regimes, the harmonization of species nomenclature is to be addressed as a standing item. ${ }^{163}$ In this way, the influence of the CSAB is likely to be less visible, pervading decision making and unifying practical methodologies within the various scientific institutions at an individual and collective level.

\section{MOU-Based Approaches}

Notwithstanding the developments towards collective practices, the elaboration of MOUs between individual treaties remains the most entrenched and, potentially, effective means of promoting integrative policies among the BRCs. These arrangements tend to follow a broad pattern, commencing with the negotiation of an instrument of co-operation, which may be subsequently bolstered by COP pronouncements and the development of joint activities. This general trend emerged in 1996 with the conclusion of a MOC between the Ramsar Convention's Bureau and the CBD's Secretariat, which was to be the first of many such documents concluded between the BRCs and other pertinent actors. MOCs/MOUs have been concluded by the CBD with all of the other BRCs, while a number of these regimes have concluded similar instruments with each other-and, indeed, with the various daughter agreements under the CMS. Political impetus towards servicing the MOUs is provided by the formal pronouncements of the various COPs, exemplified by the CBD's conferral of 'lead partner' status to the Ramsar Convention ${ }^{164}$ and to the $\mathrm{CMS}^{165}$ in addressing wetland considerations and migratory species respectively. COP decisions supporting further co-operation between conventions are legion, while further

160 H. MacKay and S. Alexander, Towards a Multi-Convention Collaboration on Ecosystem Restoration, discussion paper presented at the Fourth Meeting of CSAB (2011).

161 Report of the Fourth Meeting of Chairs, supra note 155 at 1-3.

162 CBD, supra note 8, Article 6.

163 Report of the Fourth Meeting of Chairs, supra note 155, at 8.

164 Decision III/21 on the Relationship of the Convention with the Commission on Sustainable Development and Biodiversity-related Conventions, Other International Agreements, Institutions and Processes of Relevance (1996).

165 Decision VI/20 on Cooperation with Other Organizations, Initiatives and Conventions (2002). 
synergistic impetus is provided through periodic strategic plans that the BRCs routinely establish for themselves, again following a trend pioneered by the Ramsar Convention.

The MOUs adopted to date have generally been concise documents, characterized by amiable vagueness and typically pledging greater institutional co-operation, information exchange, and mutual representation at meetings of interest. Many MOUs also include more open-ended possibilities towards streamlining conservation policies, the potential harmonization of administrative practices, and joint programs of activity. Nevertheless, in and of themselves, such MOUs contribute little more than platitudinous statements of endeavour. As Nele Matz observes, '[t]he general will to co-operate, even if repeated in decisions of the Conferences of States Parties, is not sufficient, but rather needs implementation.' 166 While MOUs exemplify a commendable intention to advance such implementation, they have added relatively little to effective synergies unless accompanied by clear, targeted, realistic and partner-specific programs of work.

The first practical initiatives to implement MOU objectives were developed through the $\mathrm{CBD}$, although these initial activities had an ultimately modest impact. In 1997, a pioneering Joint Work Programme (JWP) was concluded between the Ramsar Bureau and the CBD Secretariat to seek to advance the broad co-operative themes outlined in the earlier MOC on a more practical basis. A similar initiative was developed between the CBD and its other 'lead partner,' the CMS, in 2002. The JWPs have been revised and refreshed on numerous subsequent occasions in line with further guidance from the respective COPs. However, early incarnations of the JWPs tended to be extremely vague and, in retrospect, generated few tangible projects between treaties.

The first CBD-Ramsar JWP essentially sought to identify advisory roles and potential administrative synergies, albeit without particular targets and with relatively few specific projects in mind. A second JWP for 2000-01 introduced a degree of target setting, primarily concerning the review of outputs and assisting in the practical implementation of convention commitments alongside a concerted effort to streamline reporting obligations. Meanwhile, in the context of the CMS, these arrangements were conversely undermined by a surfeit of targets and a concomitant lack of operational coherence. Virtually all of the action points in the first CBD-CMS JWP were accorded a 'high' priority, requiring implementation before the end of $2003 .{ }^{167}$ Indeed, the only objective considered a 'low' priority was the need to 'develop legislation for the protection and conservation of migratory species, as appropriate.' ${ }^{168}$ Ironically, given that

166 N. Matz, Chaos or Coherence? Implementing and Enforcing the Conservation of Migratory Species through Various Legal Instruments 65 Zeitschrift für ausländisches öffentliches Recht und Völkerrecht 197 at 211 (2005).

167 CMS-CBD Joint Work Programme, Doc. UNEP/CMS/Inf.7.13 (2002).

168 Ibid., Action 15.3 
the $\mathrm{CBD}$ champions the development of co-ordinated national activity towards biodiversity conservation, this particular objective would seemingly constitute the most tangible and permanent benefit of synergy. In the case of CITES, the JWP's approach has been short-lived, with only one such instrument developed with the CBD for 2000-02, which centred around co-operation on economic incentives, green labelling, plant conservation, and bushmeat concerns.

Despite these initial shortcomings, more recent JWPs have marked a shift in policy away from more esoteric administrative streamlining between treaties in favour of improved synergies at the national level. Indeed, the key CBD obligation for parties to establish NBSAPs presents further opportunities to streamline cumulative BRC commitments within domestic conservation strategies. This policy was reinforced by the CBD at its tenth COP as a key strategy for implementing the revised global biodiversity targets. ${ }^{169}$ The third CBD-Ramsar JWP, which was operational between 2002 and 2006, coincided with a revised MOC that reinforced mutual commitments towards ensuring consistency between national wetlands policies under the Ramsar Convention and the NSBAPs developed under the CBD. This approach was put into practice in a fourth JWP developed for 2007-10, which allocated primary responsibility to the national focal points for promoting operational synergies. Under this initiative, parties may identify particular national actions, based on domestic priorities, for which the focal points established under the two conventions are to 'cooperate in a proactive and flexible way' towards implementation. A fifth JWP is currently under development, which is likely to follow a similar model over an extended timescale towards 2020 .

This approach was replicated in the second CBD-CMS JWP, which was operational in 2006-08 and which also prioritized linkages between the national focal points. The CBD subsequently advocated reinforcing JWP arrangements, with particular emphasis on "providing support and guidance to Parties on the integration of migratory species considerations in national biodiversity strategies and action plans. ${ }^{170}$ The CMS has developed a series of guidelines to promote the implementation of convention commitments within the NBSAPs. ${ }^{171}$ Significantly, they promote a clearer focus upon synergies on a national 'grassroots' basis, as opposed to the more abstract executive levels. ${ }^{172}$ Similarly, CITES has sought to improve synergies on a national level by assisting

169 The executive secretary of the CBD is required to '[c]ollaborate with the secretariats of the other biodiversity-related conventions to facilitate the participation of national focal points of these agreements, as appropriate, in the updating and implementation of national biodiversity strategies and action plans and related enabling activities.' Decision X/5 on the Implementation of the Convention and the Strategic Plan (2010).

170 Decision X/20, supra note 141 .

171 Resolution 10.18 on Guidelines on the Integration of Migratory Species into National Biodiversity Strategies and Action Plans and other Outcomes from CDB COP-10 (2011).

172 Indeed, the guidelines pointedly criticized previous synergy initiates as being 'focused largely on processes at the international level.' Ibid. at 17. 
mutual parties in integrating complementary activities within their NBSAPs, ${ }^{173}$ and it has also developed distinct guidelines to this end. ${ }^{174}$

The change in emphasis towards promoting closer alignment between BRC commitments within the various NBSAPs presents an intriguing opportunity to improve policy coherence at a national level, not least given the near-universal participation in the CBD. Nevertheless, the value of this approach remains difficult to assess in the immediate short term, with participants in the CBD-Ramsar initiative having reported relatively few joint actions between their focal points. ${ }^{175}$ This lack of progress should perhaps not be considered unduly damning at this stage as the parties have been working to a truncated timescale in the context of other overarching priorities and with many conservation budgets slashed in the wake of the global financial crisis. However, the success of nationally orientated synergies remains fundamentally dependent upon the actions of domestic focal points. Where national resources are scarce or the responsibility for implementing international biodiversity commitments is scattered among an array of government departments, the scope for MEA institutions to influence this process on the ground remains decidedly limited.

Synergy arrangements appear to demonstrate clearer prospects for success where they are focused on species, habitats, or conservation threats of greatest overlapping interest. Crucially, it is also apparent that the conventions in question must demarcate explicit roles and responsibilities in implementing collaborative actions, which has not always been the case. Perhaps the most promising initiatives in this regard have occurred between CITES and the CMS, pursuant to an MOU concluded in 2002 pledging to ensure policy compatibility, mutual representation at meetings, data exchange, and a commitment to liaise annually to determine joint activities. ${ }^{176}$ Crucially, these generic objectives were clarified further by CITES in 2004, which identified particular species for which conservation activities under both treaties should mutually reinforce. ${ }^{177}$ While a number of subsequent CMS instruments have vaguely identified the inherent value of a CITES listing, ${ }^{178}$ joint activities between the two bodies have largely centred on the cohort of species identified by CITES Resolution 13.3, namely Saiga antelopes, snow leopards, African elephants, marine turtles, whales and

173 Notification to the Parties no. 2011/021 (2011).

174 Contributing to the Development, Review, Updating and Revision of National Biodiversity Strategies and Action Plans (NBSAPs): A Draft Guide for CITES Parties, (2011); Notification to the Parties no. 2011/026, supra note 173.

175 Joint Work Programme (JWP) between the CBD and the Ramsar Convention on Wetlands (Ramsar, Iran, 1971): Progress with Implementation and Development of the Fifth Joint Work Programme (2011 Onwards), Doc. UNEP/CBD/COP/10/INF/38 (2010) at 8.

176 Convened most recently on 2 March 2011, in a pioneering virtual meeting.

177 Resolution Conf. 13.3: Cooperation and Synergy with the Convention on the Conservation of Migratory Species of Wild Animals (2004).

178 See the preambles to the memoranda of understanding (MOUs) on African turtles, dugongs, huemuls, Indian Ocean turtles, Saiga antelopes, sharks, West African elephants, and West African marine mammals, cited in note 32 in this article. 
great white sharks, and sturgeons. CITES and the CMS outlined a first suite of joint activities for 2005-07, which focused on improving institutional practices and identifying commonalities in species coverage. A more targeted list of joint activities was developed for 2008-10, subsequently extended into $2011,{ }^{179}$ and later designated to continue towards 2014.

In identifying species of common concern, CITES and the CMS have been assisted by the listing process inherent in both treaties. Nevertheless, maintaining uniformity of species coverage has not always proven to be a simple task, as experiences with joint activities for Saiga antelope conservation attest. The Saiga antelope faces an array of conservation threats, linked both to habitat pressures and international trade, which have constituted long-standing priorities for both conventions respectively. ${ }^{180}$ While Saiga antelopes are listed on the appendices of both conventions, co-operative actions largely pre-suppose that the scientific understanding and scope of designation is identical within CITES and the CMS. ${ }^{181}$ Instead, the MOU on the Saiga antelope, as originally concluded, reflected its designated status under the parent convention at the material time and applied solely to a sub-species of this animal. In contrast, the CITES listing has traditionally applied to a wider range of species. The initial MOU thereby technically disqualified the participation of Mongolia, a key habitat state for Saiga antelope generally (but not for the sub-species Saiga tatarica tatarica that was the subject of the CMS designation) and a major importer of Saiga antelope products. These operational discrepancies, therefore, threatened to undermine the MOU's effectiveness, given the focus under CITES on Mongolian trade initiatives. In September 2010, the MOU was amended to incorporate the full range of Saiga antelope populations, allowing for Mongolian participation, and accordingly introducing greater coherence to cross-treaty efforts to protect this species. Subsequently, the value of full CITES involvement in the MOU has proven to be instrumental in attracting key signatories. Kazakhstan, a vital range state for multilateral efforts to promote Saiga antelope conservation, appears unlikely to have participated in the MOU-at least initially-without concerted pressure from CITES. ${ }^{182}$ There is also evidence of a resulting sea-change in attitudes towards Saiga antelope conservation in Kazakhstan as a result of national participation in the MOU, prompting a series

179 Summary Record of the Fifty-Ninth Meeting of the Standing Committee to CITES, Doc. SC59 Summary Record (2010) at 2-3.

180 E.J. Milner-Gulland et al., Dramatic Declines in Saiga Antelope Populations 35 Oryx 340 (2001). 181 CITES and the CMS have been working closely to standardize species nomenclature between the two conventions. see Recommendation 9.4 on Standardized Nomenclature for the CMS Appendices (2008). Both conventions have pledged continuing co-operation on this issue - both jointly and in association with the Scientific Advisory Boards (CSAB) - to ensure that this practice becomes standard across the BRCs.

182 Questionnaire Submitted by the Saiga MOU to Phase One of the Working Group on the CMS Future Shape Process [on file with the author]. 
of significant legislative adjustments. ${ }^{183}$ Moreover, the clearer application of the MOU to the full range of Saiga antelope species has allowed CITES to prioritize collaboration with the CMS in its central Asia program, ${ }^{184}$ including cost-sharing, administrative streamlining, and a series of joint conservation meetings for the Saiga antelope. ${ }^{185}$

Similarly, a striking example of inter-treaty synergies in responding to a common threat is presented by the response of the African-Eurasian Waterbird Agreement (AEWA), the Ramsar Convention, and the CMS to the avian influenza crisis. In August 2005, following the H5N1 outbreak, the CMS established a Task Force on Avian Influenza and Wild Birds with the assistance of the UN Food and Agriculture Organization and incorporating a number of pertinent actors, specifically including AEWA and the Ramsar Convention. ${ }^{186}$ Following this initiative, the CMS, AEWA, and Ramsar Convention institutions formulated an integrated response to the crisis, framed by executive resolutions adopted in close co-operation with their scientific bodies. ${ }^{187}$ A series of common approaches have emerged from these resolutions to unify future policies towards avian influenza. Both AEWA and the Ramsar Convention have called for a policy of restraint, stating that culls of waterbirds and the destruction of habitats are misguided and do not constitute the 'wise use' of wetlands. All three regimes have observed the need for improved data collection and swift analysis, integrated mitigation responses between all relevant stakeholders, the development of emergency responses and capacity-building programs, and a unified scientific response. The CMS Task Force convened a workshop in 2007 on practical lessons learned, the outcomes of which were also endorsed by these actors. In turn, the Ramsar Convention's STRP has developed practical guidance on avian influenza responses, which has been endorsed by the CMS in framing future disease strategies. ${ }^{188}$

These initiatives demonstrate that, allied to common species or thematic considerations, clear lines of responsibility must be drawn between treaties in developing effective programs of work. Thus far, CITES and the CMS have

183 Anonymous, Kazakhstan Believes it a Point of Honor to Stop Illegal Hunt of Saigas 12 Saiga News 7 (2011).

184 Decision 14.97: Saiga Antelope (2007).

185 Indeed, the two Meetings of the Signatories having been jointly organized and financed by the CMS and CITES, alongside a significant joint workshop convened in association with the Chinese CITES authorities.

186 Resolution 9.8: Responding to the Challenge of Emerging and Re-Emerging Diseases in Migratory Species, Including Highly Pathogenic Avian Influenza H5N1 (2008).

187 Resolution 3.18: Avian Influenza, (2005); Resolution 4.15: Responding to the Spread of Highly Pathogenic Avian Influenza H5N1 (2008) (AEWA); Resolution IX.23: Managing Wetlands and Waterbirds in Response to Highly Pathogenic Avian Influenza (2005); Resolution X.21: Guidance on Responding to the Continued Spread of Highly Pathogenic Avian Influenza H5N1 (2008) (Ramsar Convention); Resolution 8.27: Migratory Species and Highly Pathogenic Avian Influenza (2005) and Resolution 9.8, supra note 186 (CMS).

188 Resolution 10.22: Wildlife Disease and Migratory Species (2011) (exhorting parties to 'use and promote the Ramsar Disease Manual' in managing diseases). 
outlined a series of potential actions across the coming triennium to promote joint policies, largely through convening joint meetings and participating in fora of mutual interest. This has been a generally successful policy in the context of African elephants where key CITES programs-Monitoring the Illegal Killing of Elephants (MIKE) and the Elephant Trade Information System ${ }^{189}$ - have worked closely with the CMS's Elephant MOU. ${ }^{190}$ Both meetings of the signatories convened to date have been attended by CITES-MIKE and have been followed immediately by joint meetings of the two bodies to ascertain future co-operation, generating a series of important allied policies. In June 2008, a workshop organized by the CMS during the Pan-African CITES-MIKE meeting resulted in a program of activity for transboundary areas within a number of mutual parties, for which clear partnership roles for conservation efforts were developed and arranged. ${ }^{191}$ Specific roles for both treaties are also demarcated within the MOU's Medium-Term International Work Programme, while future areas of co-operation include broader conservation measures, continued attention to the transboundary activities program, and ongoing training of personnel. ${ }^{192}$ Such efforts are considered 'an important relationship benefiting the region's Central African elephant conservation work, and serves to ensure complementarity between the work of the two Conventions.' ${ }^{193}$ Of potentially greater significance, the recent demarcation of responsibility for cetaceans between the CMS and numerous multilateral regulators should improve governance of an issue long bedevilled by treaty congestion. ${ }^{194}$ Nevertheless, despite the clear value of these projects, precise inter-treaty relationships have yet to be established for a vast array of species, which presents practical difficulties for the development of effective synergy arrangements in this manner.

\section{FACTORS INHIBITING FURTHER CO-ORDINATION}

The previous discussion reveals that promising initiatives have emerged in recent years with the potential to deliver improved resource and conservation benefits in the mid-term future. Nevertheless, considerable challenges remain to the formation and maintenance of effective linkages between the BRCs. Three considerations may be considered particularly exigent. First, beyond general motivations to avoid policy duplication and conflict, the precise objective of

\footnotetext{
189 Resolution Conf. 10.10: Trade in Elephant Species (1997).

190 MOU Coordination, Doc. UNEP/CMS/WAE2/Doc 7 (2011), presented at the Second Meeting of the Signatories in June 2011, at 3.

191 Declaration of the Joint-Meeting of the CMS-MoU/CITES-MIKE, Doc. UNEP/CMS/WAE/1/Inf.6 (2009) at 3.

192 Second Joint Meeting of the CMS-MoU/CITES-MIKE, provisional agenda, Doc. UNEP/CMS/ WAE2/Doc.1/Rev.1 (2011).

193 K. Lindsay et al., Analysing Gaps and Options for Enhancing Elephant Conservation in Central Africa, Doc. UNEP/CMS/Inf.10.27 (2011) at 35.

194 Resolution 10.15: Global Programme of Work for Cetaceans (2011).
} 
synergy arrangements has been little explored. Second, the working practices of many conventions are not conducive to promoting co-operation between them. Third, and perhaps most significantly, resource constraints continue to undermine the capacity of MEAs to maintain effective linkages.

\section{Strategic Uncertainty}

The traditional aim of synergy arrangements has been to mitigate the problems associated with so-called 'treaty congestion' in order to maximize operational coherence and to ensure that pressurized financial and human resources are not squandered through the needless duplication of administrative and conservation efforts. ${ }^{195}$ Beyond these laudable objectives, the precise rationale for inter-treaty co-operation remains somewhat uncertain.

Where synergy arrangements are designed to promote a particular conservation policy, questions of leadership remain. Difficulties have occasionally arisen within the confines of the BLG, which is driven essentially by the CBD-especially during its initial period of operation, in which a strong emphasis was placed on the aggregation of common approaches to meet CBD-driven commitments. There have been varying degrees of endorsement for a 'CBD-ification' of strategic management across the various BRCs. With respect to the ITPGRFA, close alignment with the CBD remains a central treaty commitment. The Ramsar Convention has ultimately been prepared to amend fundamental working principles to accommodate CBD concerns. Interactions with the CBD have prompted a reformulation of key Ramsar commitments towards the 'wise use' of wetlands, ${ }^{196}$ away from the 'benefit of mankind, ${ }^{197}$ to explicitly incorporate the ecosystem approach, ${ }^{198}$ which the CBD Secretariat has quietly considered to be one of its greatest collaborative achievements. ${ }^{199}$ Strikingly, a series of subsidiary instruments developed by the CMS since 2003 were primarily motivated by 'international responsibilities... pursuant to the Convention on Biological Diversity' and the status of the parent convention as its lead partner, with specific commitments under the CMS being rather less explicit. ${ }^{200}$ While the BRCs have endorsed the overarching CBD biodiversity targets and consider them a useful reference for their individual commitments, a CBD-centric approach has nonetheless rankled on occasion. In particular, CITES has proven reluctant to

195 Decision II/13 on Cooperation with Other Biodiversity-related Conventions (1995) (seeking 'to avoid unnecessary duplication of activities and costs on the part of Parties and of the organs of the Convention').

196 Ramsar Convention, supra note 4, Article 3.3.

197 Recommendation 3.3: Wise Use of Wetlands (1987).

198 Resolution IX.1: Additional Scientific and Technical Guidance for Implementing the Ramsar Wise Use Concept (2005) at Annex A.

199 B. Siebenhüner, Administrator of Global Biodiversity: The Secretariat of the Convention on Biological Diversity 16 Biodiversity Conservation 259 at 267 (2007).

200 See the preambles to the Aquatic Warbler MOU, West African Elephants MOU, Saiga MOU, Pacific Islands Cetaceans MOU, Mediterranean Monk Seal MOU, and Western Marine Mammals MOU, cited in note 32 in this article [emphasis added]. 
commit pressurized resources to measure performance towards what are effectively $\mathrm{CBD}$ priorities, which were formulated without the involvement of the other Secretariats. ${ }^{201}$

Ultimately, the direction of synergy arrangements cannot be considered in isolation to wider questions concerning the future operation of the treaties themselves. This is already a live issue within the CMS, which is currently re-evaluating its long-term structure and remit. ${ }^{202}$ It has been suggested that operational concerns could be mitigated by aggregating these treaties more formally within the auspices of the CBD. ${ }^{203}$ These calls have been echoed in specific CMS subsidiary instruments. ${ }^{204}$ The CMS has attempted to achieve closer strategic alignments in this manner by merging some of its MOUs with instruments and actors from allied institutions. These initiatives remain embryonic, but it should also be remembered that it involves the fusion of less-formal institutions. However, binding agreements have strenuously guarded their autonomy, fearing that their niche mandates would be lost with their absorption into a wider entity. ${ }^{205}$ Doubts remain whether neat annexations are either feasible or desirable. In the meantime, it appears that the BRCs will continue as independent bodies, with recent clear recognition of their individual roles and distinct legal status. ${ }^{206}$

\section{Disparate Working Practices}

A consistent impediment to improving multilateral synergies remains the working practices of the conventions themselves, which operate on disparate timescales, with different administrative and monitoring procedures, and with fragmentary methods of policy making. A long-standing complaint of national operators concerns the traditional lack of alignment in monitoring requirements, with MEAs demanding similar information in different formats compounded by fluctuating reporting deadlines. Accordingly, the harmonization of administrative practices has long constituted an operational priority for UNEP. Despite a multitude of reports and pilot projects, there remains little prospect of a universal solution to this problem.

\footnotetext{
201 See the comments of CITES as recorded in the Report of the Fifth Meeting of the Liaison Group, supra note 154 at 2; Report of the Sixth Meeting of the Liaison Group, supra note 142 at 4.

202 Resolution 10.09: Future Structure and Strategies of the CMS and CMS Family (2011).

203 Jóhannsdóttir, Cresswell, and Bridgewater, supra note 10 at 147-49.

204 R. Churchill, Sustaining Small Cetaceans: A Preliminary Evaluation of the Ascobans and Accobams Agreements, in A. Boyle and D. Freestone (eds.), International Law and Sustainable Development: Past Achievements and Future Challenges (2001) at 244.

205 Report of the Thirteenth Meeting of the Advisory Committee to ASCOBANS, Doc. AC13-Report (2006) at 8.

206 As articulated by the CBD (Decision X/20, supra note 141), the Biodiversity Liasion Group (Principle 2 of the Modus Operandi, supra note 146, 'recognises the distinct and specific objectives of each convention and their different Parties, as well as the individual mandates and independent status of their treaty bodies and Secretariats'), and the UN General Assembly (UN General Assembly Resolution 65/161: Convention on Biological Diversity, Doc. A/Res/65/161 (11 March 2011) at para. 11).
} 
Beyond the difficulties experienced by national bodies, it is increasingly difficult to map the specific policies pursued by the BRCs on particular issues, which further inhibits potential synergies. In recent years, there has been a steady proliferation of working groups, committees, processes, institutions, and actors, some of which may have only a transient existence. This increasing fragmentation 'is not only an obstacle for law makers involved in the implementation of the convention at the national level, but also for negotiators willing to ensure mutual supportiveness of the convention in other international processes. ${ }^{207}$ Tracking the precise outputs of subsidiary bodies, thematic strategies, work plans, and allied initiatives across even a narrow range of specialist treaties such as the BRCs requires considerable detective work on the part of interested observers. Some relief may be provided through new mapping initiatives, notably the United Nations Information Portal on Multilateral Environmental Agreements (InforMEA), which was launched in June 2011, establishing a thematic database of policies from a range of MEAs. ${ }^{208}$ Nevertheless, as noted in the following discussion, practical difficulties have already become apparent in promoting the optimal use of this portal.

Thus far, considerable emphasis has been placed within the BLG on unifying the working practices of the BRCs. However, instead of seeking to unite the six conventions centrally-for which the number of universal thematic and species priorities may be minimal - it would appear more logical to align particular working groups and side meetings as far as practicable. Where these various working groups and single-species initiatives can be clearly identified, past experiences outlined earlier suggest that this approach can be highly effective.

Synergies between CITES and the CMS have been greatly assisted by identifying species of common concern and highlighting opportunities to develop co-ordinated policies through joint workshops and working groups. Both treaties also work collaboratively to ensure the uniformity of species coverage to maximize synergy opportunities. Similar considerations are also apparent between CITES and the CBD, especially concerning bushmeat, for which both conventions have established distinct working groups. In June 2011, the CBD Liaison Group on Bushmeat organized a joint meeting with the CITES Central African Bushmeat Working Group, generating an extensive program of recommendations to be taken individually and in partnership. ${ }^{209}$ Significantly, these arrangements served to re-energize the CITES group, a stagnating forum that had failed to report to the Standing Committee in over three years. ${ }^{210}$

\footnotetext{
207 E. Morgera and E. Tsioumani, The Evolution of Benefit Sharing: Linking Biodiversity and Community Livelihoods 19 RECIEL 150 at 173 (2010).

208 See Informea, online: <http://www.informea.org >

209 Revised Recommendations of the Convention on Biological Diversity Liaison Group on Bushmeat, Doc. UNEP/CBD/SBSTTA/15/12 (2011) at 10-14.

210 Outcomes of the Joint Meeting of the CBD Liaison Group on Bushmeat and the CITES Central Africa Bushmeat Working Group, Doc. UNEP/CBD/LG-Bushmeat/2/4 (2011) at 4.
} 
Beyond this action, however, it would appear that a direct synchronization of working practices is only feasible within specific and closely aligned MEAs. One current initiative of particular significance involves streamlining the working practices of the Ramsar Convention and AEWA, which has a clear scope to deliver enhanced operational benefits. AEWA mirrors the Ramsar Convention's structure in a number of key respects, ${ }^{211}$ including a provision for a small grants fund $^{212}$ to promote data gathering and localized conservation initiatives. Technically, AEWA has long supported the International Waterbird Census conducted by Wetlands International, which constitutes an integral source of data for present and potential Ramsar Convention sites. ${ }^{213}$ Provision also exists for joint implementation activities in areas of mutual concern. The wetlands convention has developed an innovative implementation mechanism, the Ramsar Advisory Mission (RAM), which mandates on-site inspection and remedial advice. ${ }^{214}$ In 2008, AEWA launched a parallel initiative, the Implementation Review Process (IRP), with its Standing Committee charged with ensuring that it operates 'in mutual cooperation with other relevant agreements to eliminate any possibility of duplication.' ${ }^{215}$ Mutual reinforcement of the Ramsar implementation process is already conducted under AEWA, with the Standing Committee involved in follow-up activities for recommendations arising under RAMs in common areas. ${ }^{216}$ Likewise, since 2009, AEWA has assisted directly in RAMs in areas of joint concern. ${ }^{217}$ The launch of the IRP, while still in its relative infancy, raises the possibility of further joint missions in the mid-term future as a key implementation strategy for both regimes. Most significantly, AEWA has committed itself to convening its MOP quadrennially to follow the Ramsar timetable. ${ }^{218}$ It is further envisaged that meetings will be closely scheduled, 'since it was vital that synergies between AEWA and Ramsar be maximised.' 219 However, concerns were raised by potential financial and operational difficulties arising from operating on an extended timescale, ${ }^{220}$

211 AEWA correlates closely with the work of the Ramsar Convention and is considered an important hub for multilateral activities. R. Adam, Waterbirds, the 2010 Biodiversity Target, and Beyond: AEWA's Contribution to Global Biodiversity Governance 38 Envt'1 L 87, at 122 (2008).

212 Resolution 1.7: Establishment of a Small Grants Fund (1999). The fund was finally launched officially in 2010.

213 Resolution 2.4: International Implementation Priorities for 2003-2007 (2002).

214 Recommendation 4.7: Mechanisms for Improved Application of the Ramsar Convention (1990).

215 Resolution 4.6: Establishment of an Implementation Review Process (2008).

216 Report of the Sixth Meeting of the AEWA Standing Committee, Doc. STC.6_Report (2010) at 7.

217 Notably the Ramsar Advisory Missions (RAMs) conducted at the Marromeu Complex, Morocco, in August 2009 (RAM no. 62), Cayo-Loufoualba, Republic of Congo, in June 2010 (RAM no. 66), and Moulouya, Morocco, in October 2010 (RAM no. 71); reproduced on the Ramsar institutional website.

218 Report of the Fourth Meeting of the Parties to AEWA (2008) at 21.

219 Ibid. at 40.

220 Considerations about the Future Periodicity of Sessions of the Meeting of the Parties, Doc. AEWA/MOP5.43 (2012). 
and the proposed arrangements were postponed at the recent fifth Meeting of the Parties to AEWA in May 2012. ${ }^{221}$ Although the draft proposal was ultimately rejected, a number of parties remain highly supportive of this initiative, which may be revisited in the mid-term future. Should a closer alignment in meeting practices occur, as with the chemical cluster, these arrangements are likely to work effectively due to the high level of commonality in object, scope, application, and structure between the two conventions. Nevertheless, this commonality is not necessarily replicated on a more widespread basis between other BRCs, hence the scope for further similar initiatives between conventions is decidedly limited.

\section{Resource Implications}

Ultimately, and perhaps most significantly, where clear lines of activity can be identified, co-operative arrangements have often been undermined by resource constraints. While wholesale underfunding has traditionally bedevilled MEAs, particular difficulties have been experienced in securing the requisite financial support and personnel to ensure that synergies are effectively nurtured. Few of the BRCs maintain designated liaison officers, with synergy tasks falling on already over-burdened Secretariats. Ad hoc staff transfers between Secretariats occasionally relieve the pressure, alongside a steady stream of interns, yet it remains clear that neither policy represents an effective long-term solution to synergy demands. ${ }^{222}$ Individual donations to support governance projects are sporadic, although effective when they are forthcoming. France contributed $€ 95,000$ to underwrite the costs of identifying future areas of co-operation between CITES and the CMS, ${ }^{223}$ alongside further donations from Monaco, ${ }^{224}$ yet this source of funding remains irregular, finite, and unpredictable for such initiatives. The BRCs have generally struggled to generate the sustained private sector and corporate funding that could advance such projects further. ${ }^{225}$

221 The formal report of the MOP was not available at the time of writing. See instead the unofficial contemporaneous reporting of the meeting by the International Institute for Sustainable Development Reporting Services Division, online: < http://www.iisd.ca.cms/aewa-mop5>. The MOP did, however generate a resolution identifying additional possibilities for administrative and technical synergies, including the harmonization of designation criteria, common communication strategies, and a greater co-ordination between expert bodies. See Resolution 5.19: Encouragement of Further Joint Implementation of AEWA and the Ramsar Convention (2012).

222 Report on Resource Mobilization, Doc. UNEP/CMS/Conf.10.19 (2011) at 4.

223 Cooperation with Other Organisations: Convention on the Conservation of Migratory Species of Wild Animals, Doc. SC61 15.4 (Rev. 1) (2011) at 2.

224 Report on Resource Mobilization, supra note 222 at 4.

225 Nevertheless a greater degree of emphasis has been placed on private-sector engagement by a number of the BRCs in recent years. The CMS has appointed a Fundraising and Partnerships Officer, while the Ramsar Convention has developed principles on business partnerships. See Resolution X.12: Principles for Partnerships between the Ramsar Convention and the Business Sector (2008). This was reinforced by Resolution XI.20: Promoting Sustainable Investment by the Public and Private Sectors to Ensure the Maintenance of the Benefits People and Nature Gain from Wetlands (2012), calling for the facilitation of increased invenstment to this end. 
Likewise, the long-term success of effective synergy projects is frequently imperilled by ongoing financial constraints. This problem could jeopardize a number of nascent syngery practices, including potential strategic alignments through the CBD's NBSAP program. Indeed, the CMS recently lamented that 'sufficient funds have not been received to assist national implementation through capacity building and the effective participation of CMS focal points in the NBSAP regional and national processes. ${ }^{226}$ Financial pressures have also undermined flagship conservation projects. The AEWA's Wings over Wetlands program, which is a pioneering initiative to support a variety of field projects and one of the most tangible examples of inter-treaty synergies, recorded a financial shortfall of $€ 1$ million over the 2006-08 triennium, thereby leaving thirteen out of its fifteen international implementation priorities without a source of funding. ${ }^{227}$ Likewise, as noted earlier, financial considerations were a key factor in the decision by AEWA to postpone further administrative alignment with the Ramsar Convention. Furthermore, in the mid-term, many BRCs currently lack the requisite information and communications technology capacity to fully participate in, and access, the InforMEA portal, which was designed specifically to aid communication and synergy possibilities between treaties. ${ }^{228}$

\section{CONCLUDING REMARKS}

Since the inception of the CBD, BRCs have vigorously pursued integrative policies as an operative priority. Despite a considerable collective investment of time and resources, various state parties have legitimately questioned whether such endeavours have generated meaningful ecological or administrative improvements. While this article considers that the picture is not entirely bleak-in some cases, particularly with respect to waterbird initiatives, there is some cause for genuine optimism-it is also suggested that clear strategic improvements could be made to current governance initiatives. This article considers that smaller synergy projects that are adequately supported and provide clarity of purpose, objective, and responsibility should be adopted as the optimal model of inter-treaty co-operation in the biodiversity sector. Bridges must be built on clearly identifiable foundations of mutual interest rather than by pursuing vague objectives to uniformly align a highly disparate group of treaties notable more for their divergent features than their overriding commonality.

Significant problems remain in promoting effective synergy arrangements between the BRCs that will inhibit future prospects for success. The convention structures are unwieldy with divergent institutional priorities. It is not always apparent, moreover, what the long-standing desire for synergy is ultimately

\footnotetext{
226 Report on Resource Mobilization, supra note 222 at 6.

227 Report of the Fourth Meeting of the Parties to AEWA, supra note 218 at 15.

228 Online National Reporting, Harmonization of Information and Knowledge Management for MEAs, Doc. UNEP/CMS/Conf.10.10 (2011).
} 
intended to achieve. Co-operative arrangements are frequently devoid of clear and targeted outcomes. Where clarity of direction does exist, it is all too often unaccompanied by the resources to deliver its objectives on a long-term basis. Likewise, administrative linkages to promote biodiversity conservation must necessarily extend beyond the confines of these regimes. While a small number of treaties have been ostensibly christened 'biodiversity related,' a great many others will relate to biodiversity. Ultimately, as the CSAB has advised, '[c]ollaboration should not be seen as a magic solution and it is important to carefully evaluate the transaction costs and avoid numerous additional meetings. ${ }^{229}$ With synergy arrangements considered an even greater institutional priority in the post-2010 biodiversity landscape, these sentiments may prove to be wise counsel indeed.

229 Report of the Third Meeting of Chairs, supra note 158 at 6. 